\title{
Nucleic Acid Carriers Based on Precise Polymer Conjugates
}

\author{
Christina Troiber and Ernst Wagner* \\ Pharmaceutical Biotechnology, Center for System-based Drug Research and Center for NanoScience (CeNS), \\ Ludwig-Maximilians-Universität, Butenandtstrasse 5-13, 81377 Munich, Germany
}

ABSTRACT: Polymer polydispersity, random conjugation of functional groups, and poorly understood structure-activity relationships have constantly hampered progress in the development of nucleic acid carriers. This review focuses on the synthetic concepts for the generation of precise polymers, site-specific conjugation strategies, and multifunctional conjugates for nucleic acid transport. Dendrimers, defined peptide carriers,

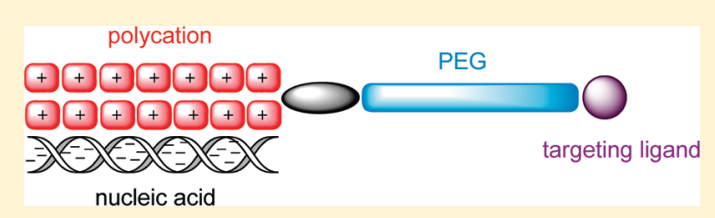
sequence-defined polyamidoamines assembled by solid-phase supported synthesis, and precise lipopeptides or lipopolymers have been characterized for pDNA and siRNA delivery. Conjugation techniques such as click chemistries and peptide ligation are available for conjugating polymers with functional transport elements such as targeting or shielding domains and for direct covalent modification of therapeutic nucleic acids in a site-specific mode.

\section{INTRODUCTION}

A prerequisite for the successful delivery of genetic information into target cells of patients is the existence of appropriate carriers. Efficient viral and synthetic vectors already exist for the ex vivo nucleic acid delivery, whereas efficient and successful in vivo transport of DNA, RNA, or small interfering RNA (siRNA) to target cells is still limited. In terms of efficiency, viral vectors are still the most potent systems. Nonetheless, synthetic vectors possess distinct advantages, such as a lower immunogenic potential, a reduced mutagenic risk, and easier handling and manufacturing. ${ }^{1-4}$ A combination of both worlds, the design of "synthetic viruses", might be most advantageous. ${ }^{5-8}$

Anionic charge, large size, and degradability of nucleic acids by nucleases make administration of naked nucleic acids rather inefficient in reaching the target location. ${ }^{9,10}$ For these reasons, special carriers have been developed to aid the delivery of genetic material. They are designed to protect nucleic acids in the extracellular environment and to mediate their transport into the cytoplasm. ${ }^{11}$ Several barriers, including stickiness to nontarget cells, extracellular fluids, and matrix, have to be overcome. ${ }^{12}$ Cell entry, endolysosomal escape, cytoplasmic trafficking, and vector unpacking are further bottlenecks for successful delivery. ${ }^{13-15}$ In the case of gene delivery the functional plasmid DNA (pDNA) encoding the protein has to be delivered into the nucleus. ${ }^{16}$

The most common synthetic vectors are cationic lipids and polymers, which form electrostatic complexes with the negatively charged nucleic acid. The payload is packaged into nanosized structures enabling uptake into cells. ${ }^{14,17}$ In the case of polymers, the polyplex stability and transfection efficiency depend on the chemical type, molecular weight, and topology of the cationic polymer, as well as the ratio of polymer to nucleic acid. ${ }^{18-20}$ Polyamine structures, including poly-L-lysine, linear and branched polyethylenimines (PEIs), or polyamidoamine (PAMAM) dendrimers, are an often used class of artificial vector system. In some polymers such as PEI or PAMAM, only a fraction of amine groups are protonated at physiological $\mathrm{pH}$. The remaining basic groups may exhibit a buffering effect, the so-called proton-sponge effect, upon entry into the endosome. The $\mathrm{pH}$-mediated creation of new cationic polymer charges triggers an influx of chloride counterions followed by water. The resulting osmotic pressure, together with interactions of the cationic polymer with the membrane, is assumed to rupture the lysosome/endosome, releasing the carrier and its cargo into the cytosol. ${ }^{21-23}$

PEI has been one of the gold standards for polymeric $\mathrm{pDNA}$ transfer in vitro and in vivo. ${ }^{24}$ Frequently, various forms of branched PEI (bPEI) with molecular weights between 2 and $800 \mathrm{kDa}$ have been used. bPEI contains primary, secondary, and tertiary amino groups. These amines have $\mathrm{p} K_{\mathrm{a}}$ values spanning a broad $\mathrm{pH}$ range, resulting in high buffering capacity. The degree of protonation of the amines increases from roughly 20 to $45 \%$ as the $\mathrm{pH}$ decreases from 7 to $5 .^{23} \mathrm{bPEI}$ is synthesized by polymerization of aziridine and hence has a very heterogeneous and polydisperse structure.

Branched PEI and many other related polymers and their derivatives show a heterogeneous distribution of molecular weight and isomers, which significantly influences physicochemical properties, biological efficiency, and cytotoxicity. ${ }^{25-28}$ Moreover, random attachment of one or even several different functional domains results in heterogeneous conjugates that might be useful in experimental approaches, but are rather unsuitable for clinical developments. ${ }^{29}$

A possible solution to the inherent drawbacks of macromolecules derived by random polymerization is the synthesis of defined polymeric systems as nucleic acid carriers. Recently, different strategies were introduced for this purpose. Linear polymers can be generated by improved polymerization technologies, resulting in defined structures with low molecular weight polydispersity. ${ }^{30-34}$ In this way, well-defined linear PEI

\footnotetext{
Received: $\quad$ May 12, 2011

Revised: July 6, 2011

Published: July 13, 2011
} 
(LPEI) was produced in GMP quality with very acceptable biological efficiency. ${ }^{24,35}$ Early clinical studies with pDNA polyplexes highlight the potency of this polymer. ${ }^{36}$ Other defined nucleic acid carriers result from dendrimers combining an extremely low polydispersity index with the high molecular mass of classical polymers. ${ }^{37}$ Solid phase assisted synthetic strategies will be discussed for the preparation of defined polymeric structures with control over every monomer position in a sequence.

Novel efficient and orthogonal coupling techniques, as reviewed here and in other papers, ${ }^{30}$ present a recent opportunity toward perfectly defined polymers. Furthermore, precise conjugation of polymers with functional groups, such as polyethylene glycol (PEG) shielding domains, targeting ligands, or chemically synthesized oligonucleotides, allow the synthesis of homogeneous nucleic acid carrier systems with exact composition.

\section{DENDRIMERS}

Dendritic structures are built from a series of branches extending outward from an inner core. Each iteration leads to a higher generation material and therefore to dendrimers with higher molecular weight. They consist of three distinct parts: a core, branching units, and branches, which can be chemically altered independently. As a result, an enormous variety of possible dendrimers exist. ${ }^{38}$

Dendritic Polylysines. Denkewalter ${ }^{39}$ reported the synthesis of L-lysine based dendrimers (DPLs) in the early 1980s, which are usually synthesized via solid phase peptide synthesis (SPPS) introduced by Merrifield in $1963 .{ }^{40}$ Boc-protected lysines were coupled to the core repeatedly after TFA deprotection, resulting in dendritic structures of different generations $(G)$. Multiple antigen peptide (MAP) systems are a distinct type of dendritic structures containing an inner oligolysine core, multiple copies of synthetic peptide antigens, and a simple amino acid, such as alanine or glycine, as internal standard for monitoring the synthesis process. ${ }^{41}$ These systems are used in vaccines to induce immunoreactions.

Hexaethylenediamine as initiator core led to symmetrical polyL-lysine dendrimers, whereas the $\varepsilon$-peptide template, consisting of lysine residues, led to asymmetrical dendrimers. Those SPPSderived structures were well-defined and monodisperse and displayed a precise number of surface amines.

DPLs of various generations were examined for their potential as antisense oligonucleotide (ODN) and plasmid DNA carriers. ${ }^{42}$ They formed complexes with nucleic acids through ionic interactions with limited cell toxicity. The ODN and pDNA binding depended on the N/P (nitrogen to phosphate) ratios and the DPL generation. High N/P ratios and high-generation DPLs, with hyperbranched architecture, improved nucleic acid binding.

High-generation asymmetric DPLs complexed with ODN were less toxic than the free DPL. Only the highest generations of asymmetric DPLs showed moderate luciferase activity. ${ }^{42}$

The symmetric dendritic poly(L-lysine)s of generation 3 (G 3 ) or higher, built up on a hexamethylenediamine core, ${ }^{43}$ formed complexes of 200-250 nm with pDNA, whereas size did not reflect compaction strength. Especially G 5 and G 6 dendrimers showed high transfection efficiencies in Caco-2, HepG2, and MKN45 cells. The efficiency of the G 6 pDNA complex was not significantly reduced when $50 \%$ serum was added. Eighty percent and higher cell viabilities were observed for the G 6 dendrimer alone and its polyplex. With regard to in vivo distribution, DPL pDNA polyplexes were found to possess favorable characteristics,

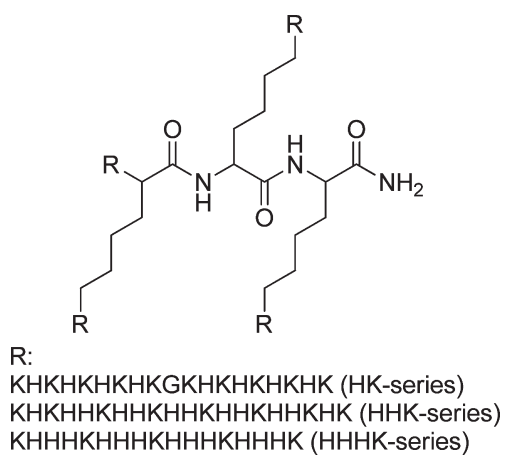

Figure 1. Dendritic copolymer of lysine and histidine.

such as delivery into tumors and prolonged circulation in the blood, but these polyplexes showed a low gene transfer efficiency. ${ }^{44}$

To investigate the effect of the terminal cationic lysine group, arginine $(\mathrm{R})$ and histidine $(\mathrm{H})$ were coupled to the surface amines of DPL G 5 resulting in DPL GR6 and DPL GH6, respectively. ${ }^{45}$ The arginine-modified DPL bound pDNA as effectively as the G 6 DPL, whereas histidine modification decreased the binding ability. Moreover, the transfection efficiency of DPL GR6 was significantly higher than that of DPL G 6, whereas DPL GH6 showed only a high efficiency when complexes were formed under acidic conditions ( $\mathrm{pH}$ 5.0) due to the protonable imidazole groups of the histidine. ${ }^{44}$

Linear copolymers of lysine and histidine were not effective in the delivery of nucleic acids. To increase the polymer size and charge density, histidine-lysine (HK) branches were attached to one, two, or three lysines, resulting in 2-, 3-, and 4- branched structures, respectively (Figure 1). ${ }^{46,47}$ The solid phase derived, branched HK dendrimers were additionally modified with branches of different histidine/lysine ratios, resulting in $\mathrm{HK}$ and HHK copolymers.

The pDNA binding and transfection efficiency positively correlates with the degree of branching and number of histidines in malignant cells with an endocytic $\mathrm{pH}>6.0$. A negative correlation was found in primary cell lines with strong acidic endosomal $\mathrm{pH}$.

For siRNA delivery the histidine/lysine ratio and branching were increased, resulting in HHHK copolymers with eight branches. ${ }^{48,49}$ The repeating pattern of HHHK on the terminal branch augmented siRNA uptake in vitro more effectively than the HHK or HK pattern. Moreover, it had a reduced binding due to the lower content of lysines, but a higher buffering capacity due to the higher number of histidines. The addition of single lysines to the eight terminal branches of the HHHK copolymer led to increased siRNA binding, but reduced silencing.

For in vivo administration, 1,2-dioleoyl-3-trimethylammonium propane (DOTAP) liposomes were used as positive control. Surprisingly, the two four-branched polymers with lower lysine content (HHHK and HHK) were more effective as carriers for intratumoral delivery of rapidly growing fibrosarcoma 1 (Raf-1) siRNA than the eight-branched polymers. The four-branched HHHK copolymer was also superior in pDNA delivery after intratumoral injection.

The amphipathic, asymmetric lysine-based dendrimers $\left(\alpha / \varepsilon\right.$ Lys $_{7^{-}}(\alpha \mathrm{AMA})_{3}$ amide and $\left(\alpha / \varepsilon \text { Lys }_{15}\right)^{-}(\alpha \mathrm{AMA})_{3}$ amide were synthesized by solid phase synthesis with 8 or 16 terminal amines, respectively. ${ }^{50}$ Both primary amines of the lysine were used to generate higher generation dendrimers $(\alpha / \varepsilon$ Lys $)$, and the terminal amines were modified with the $\alpha$-amino group of 


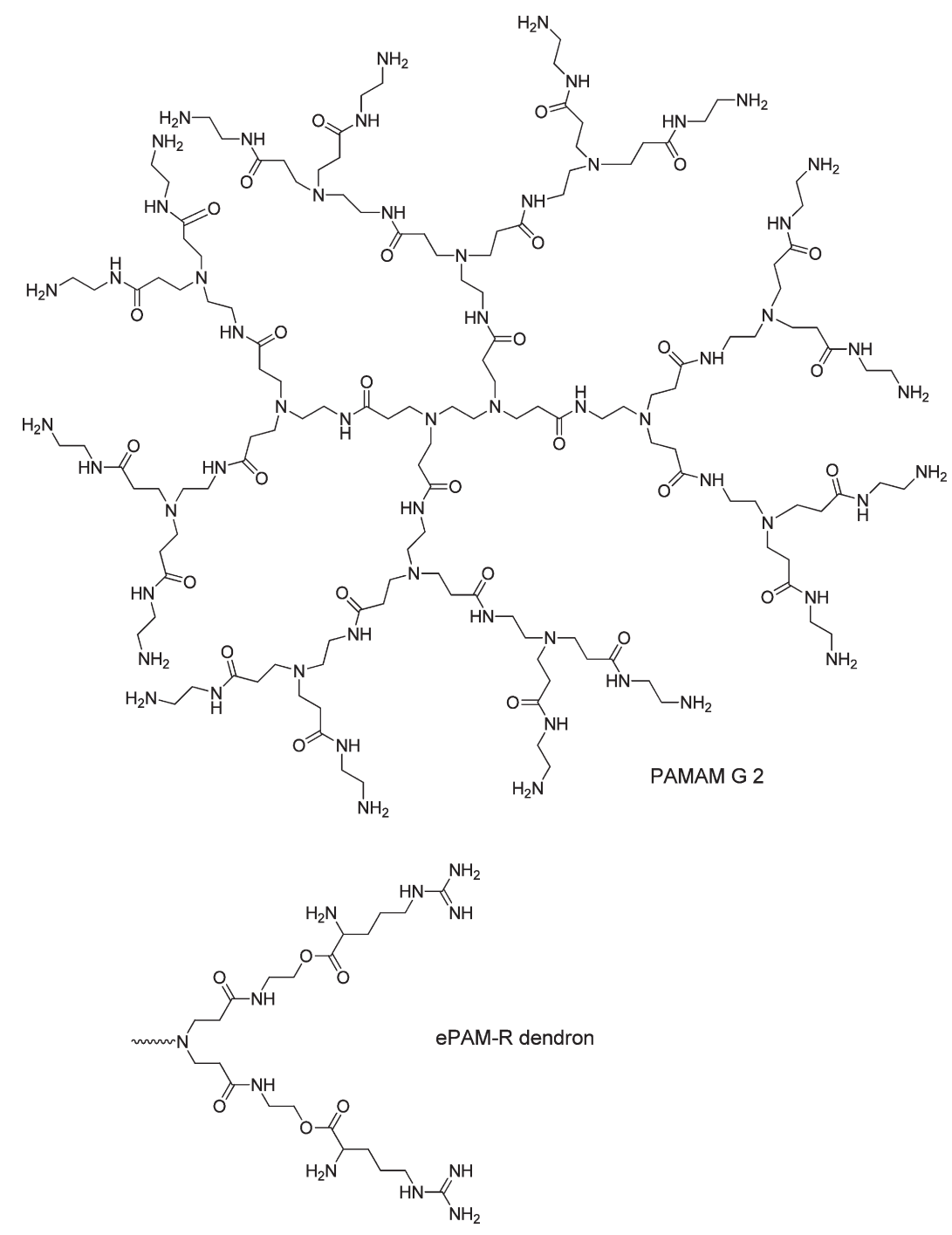

Figure 2. Starburst and arginine-grafted PAMAM dendrimer.

the amino-myristic acid (AMA). DNA dendrimer complexes formed high molecular weight aggregates with lower toxicity than the dendrimer alone. The complexes of $(\alpha / \varepsilon \text { Lys })_{15}-(\alpha \mathrm{AMA})_{3^{-}}$ amide were able to transfect BHK cells as well as COS cells. ${ }^{51}$

PAMAM Dendrimers. Starburst polyamidoamine (PAMAM) dendrimers (Figure 2) are spherical, highly ordered, dendritic polymers with positively charged primary amino groups on their surface at physiological $\mathrm{pH}$. The manufacturing process is a series of repetitive steps starting with a central initiator core. This core may consist of either an ammonium as trivalent initiator or an alkylenediamine as tetravalent initiator. Methyl acrylates are added to the core by exhaustive Michael addition followed by amidation of the resulting ester with an excess of alkylenediamine. Each complete growth step represents a new generation of polymer with a larger molecular diameter, twice the number of reactive surface sites, and approximately twice the molecular weight of the preceding generation. ${ }^{52}$

PAMAM dendrimers form stable complexes with plasmid DNA or oligonucleotides. ${ }^{53-55}$ To investigate the potential use of PAMAM dendrimers for antisense ODN delivery, antisensemediated correct splicing of a luciferase reporter was used as readout system. ${ }^{56} \mathrm{G} \geq 5$ dendrimers were moderately efficient in
ODN delivery in serum-free medium while maintaining some activity even in the presence of high serum concentrations. The luciferase expression increased progressively with increasing oligonucleotide concentration for G 5 dendrimers. Moreover, $\mathrm{G} 5$ dendrimers were less toxic in the presence of serum.

The carboxy group of Fmoc-L-arginine $(\mathrm{pbf})-\mathrm{OH}(\mathrm{R})$ or Fmoc-L-lysine(boc)-OH (K) was grafted to the primary amines of a PAMAM G 4 dendrimer, which resulted in PAMAM-R (Figure 2) or PAMAM-K dendrimers after deprotection. ${ }^{57}$ The polymers formed pDNA polyplexes with a size around $200 \mathrm{~nm}$. Compared to native PAMAM G 4 or PAMAM-K, PAMAM-R showed enhanced gene delivery expression in HepG2 and Neuro $2 \mathrm{~A}$ cell lines, as well as in primary rat vascular smooth muscle cells. The modified PAMAM dendrimers displayed an increased toxicity in comparison to native PAMAM in 293 and HepG2 cells.

To reduce the toxicity of the arginine-grafted PAMAM dendrimer, the amide bonds were replaced by more rapidly biodegradable ester bonds. Therefore, hydroxyl-terminated PAMAM-OH G 2, 3, and 4 were modified with arginine by ester bond formation, resulting in e-PAM-R G 2, 3, and 4 dendrimers. ${ }^{58}$ The core PAMAM-OH displayed low cell toxicity, transfection efficiency, 

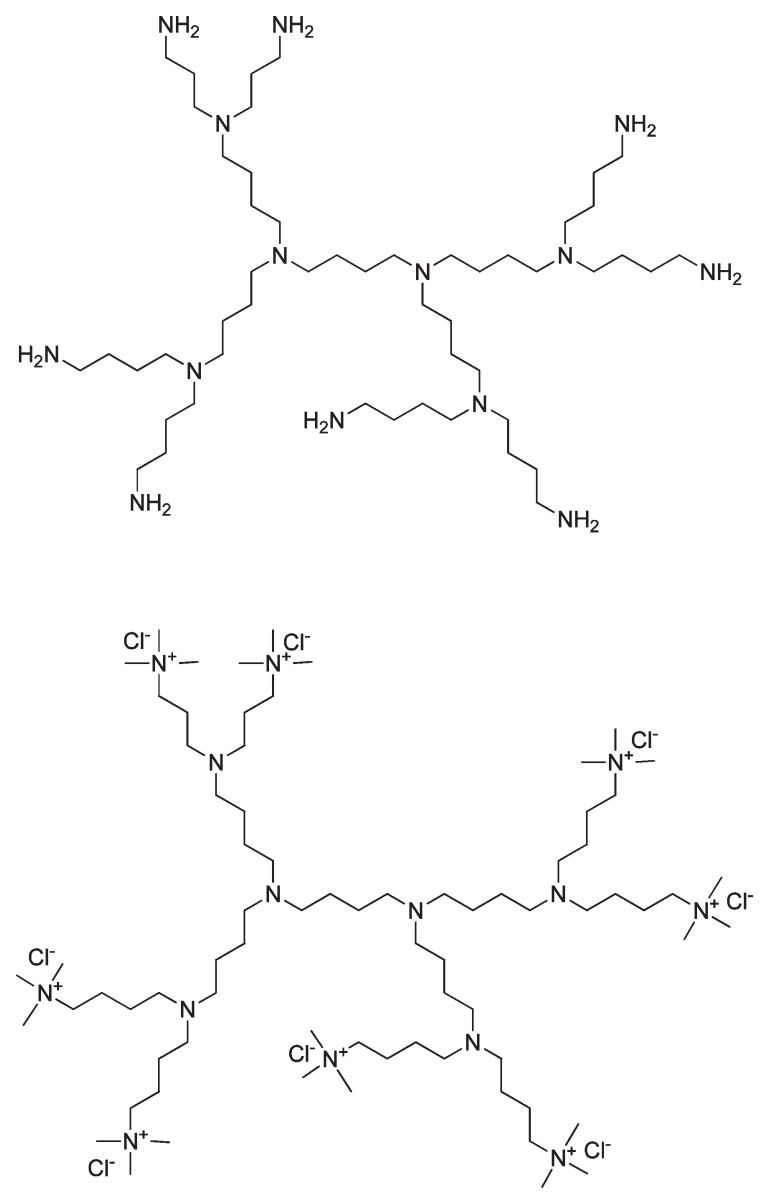

Figure 3. PPI DAB 8 and its quaternary ammonium derivative $Q 8$.

and DNA binding capacity due to the neutral hydroxyl groups on its surface. The polyplex size was $200-300 \mathrm{~nm}$, and no significant difference in DNA binding between the e-PAM-R generations was observed. The e-PAM-R G 4 showed the highest transfection efficiency, similar to PAMAM-R with favorable cell viability due to the ester bond.

The proton buffering capacity of PAMAM-K was enhanced through the introduction of one to three Fmoc-His(trt) $-\mathrm{OH}$ into the L-arginine-grafted PAMAM G 4 dendrimer. The resulting PAMAM G4-H $\mathrm{H}_{(1-3)}-\mathrm{K}$ effectively condensed pDNA at low charge ratios, and pDNA was effectively delivered into the cells, especially into the nucleus. The transfection efficiency correlated positively with the number of histidine residues in different cell lines. Cytotoxicity was relatively low in all cell lines. ${ }^{59}$

Polypropylenimine Dendrimers. Native polypropylenimine (PPI) dendrimers derived from a 1,4-diaminobutane (DAB) core of different generations (DAB 4, 8, 16, 32, and 64) and their methyl quaternary ammonium derivatives (Q 4, 8, 16, and 32) were tested for their potential as nonviral gene delivery vectors (Figure 3). ${ }^{60}$

Quaternization of the lower generation DAB 4 and 8 improved DNA binding drastically and increased vector biocompatibility. ${ }^{61}$ The toxicity of the native PPI dendrimers increased with molecular weight. DNA binding decreased the toxicity of the low-generation dendrimers, whereas the toxicity of the higher generations (DAB 16 and 32) was not modulated. DAB 16 was superior in in vitro gene transfer activity to $\mathrm{DAB} 8$, especially at low DNA doses. The DAB 8/pDNA formulations were lethally toxic, whereas Q 8/pDNA complexes were tolerated on intravenous injection. Quaternization improved cell biocompatibility of higher DAB/DNA dendrimer complexes, but reduced transfection efficiency of higher generation native dendrimers. DAB 16 and Q 8/DNA formulations resulted predominantly in livertargeted gene expression, presumably in Kupffer cells, and avoided lung delivery in contrast to LPEI.

PPI G 2 or G 3 was grafted with branched oligoethylenimine $800 \mathrm{Da}$ (OEI) or PPI dendrimer via hexanediol diacrylate, providing bioreversible ester linkages. ${ }^{62}$ Transfection levels of OEI-grafted dendrimer pDNA polyplexes were the best, similar to or even higher than those of standard PEI polyplexes. Intravenous injection of OEI-grafted PPI polyplexes into tumor-bearing mice mediated transgene expression predominantly in the subcutaneous tumors. Gene expression levels significantly increased with the higher dendrimer core generation.

\section{DEFINED PEPTIDE CARRIERS}

Key advantages of peptide polycations are monodispersity and exact composition defined by peptide sequence. This precise structure definition allows the evaluation of structure-activity relationships. Natural amino acids with cationic or protonated side chains are able to bind nucleic acids through electrostatic interactions and build positively charged polyplexes, which are then taken up through endocytosis.

Branched oligocationic peptides, which differ in number and type of cationic amino acids (lysines, arginine, ornithine) were coupled to the receptor ligand protein transferrin (Tf) via a spacer to ensure the flexibility of the peptide backbone of the pDNA binding moiety. ${ }^{63}$ The pDNA binding ability increased with the number of cationic groups, whereas variations in the cationic side chain slightly effected pDNA compaction (arginyl > lysyl $\approx$ ornithyl). Incorporating tryptophan (Trp) into the DNA binding moiety did not affect binding affinity, but did affect DNA compaction. In the presence of chloroquine, DNA complexes of peptides with six to eight cationic amino acids were able to transfect K562 cells by transferrin receptor-mediated gene delivery. ${ }^{64}$ Chloroquine acted as endosomolytic agent. ${ }^{65}$

A cationic amphipathic peptide suitable for oligonucleotide delivery contained repeating units of lysine-alanine-leucinealanine (KALA). ${ }^{66}$ The KALA peptide bound pDNA, and the complexes destabilized membranes. The efficiency of oligonucleotide delivery depended on the charge ratio. Moreover, positively charged polyplexes were necessary for nuclear accumulation and transfection.

Polyplex stabilization through interpeptide disulfide bonds was achieved by oxidation of peptides with low molecular weight after pDNA binding. Therefore, multiple cysteine residues were inserted into small synthetic oligolysines. One to four lysine residues were substituted with cysteines in Cys-Trp-Lys ${ }_{18}{ }^{67,68}$ Peptides with three or more cysteines displayed increased polyplex stability and particle size and, therefore, led to a decrease in gene transfer. The cross-linked peptide with two terminal cysteines (Cys-Trp-Lys ${ }_{17}-$ Cys) mediated maximal gene expression without increasing DNA uptake. The Cys $-\mathrm{Lys}_{4}-\mathrm{Cys}$ peptide exhibited equivalent particle size, DNA binding, and transfection efficiency. Addition of histidine resulted in the optimal peptide of Cys-His$\mathrm{Lys}_{6}-\mathrm{His}-\mathrm{Cys}$, with enhanced in vitro gene expression even in the absence of chloroquine due to its additional buffering capacity.

Another linear reducible polycation (RPC) with high molecular weight was prepared by oxidative polycondensation of 


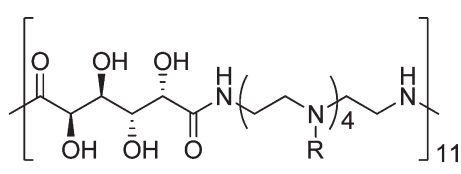

G4

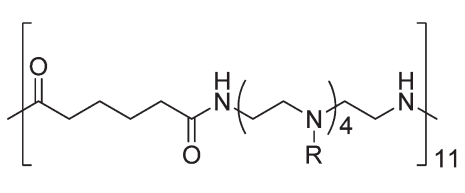

A4

Figure 4. Poly(glycoamidoamine) G4 and analogue A4.

Cys-Lys ${ }_{10}-$ Cys prior to DNA condensation. ${ }^{69}$ The cationic lipid DOTAP or chloroquine was used as endo/lysosomolytic agent for the RPC-based polyplexes. High levels of gene expression were observed in cancer cells in the presence of serum using $\mathrm{RPC} / \mathrm{DOTAP}$ polyplexes with low toxicity due to the intracellular degradation of the polycation.

A short oligoarginine synthetic peptide $\left(\mathrm{R}_{15}\right)$ showed complete condensation of siRNA $(\mathrm{N} / \mathrm{P} \geq 3)$ with particle sizes between 220 and $270 \mathrm{~nm}$ and a positive zeta potential. $^{70} \mathrm{~A}$ charge-, time-, and dose-dependent luciferase gene silencing effect was achieved with heterogeneous polyplex distribution in the perinuclear region of COS-7 cells. A significant reduction of tumor growth was observed in subcutaneous SKOV-3 tumors when treated with $\mathrm{R}_{15} / \mathrm{Her}$-2-specific siRNA. In contrast, a treatment with $\mathrm{R}_{15}$ /Her-2-mismatch siRNA, naked siRNA, or $5 \%$ glucose solution showed no growth inhibition. Those results were confirmed with Western blot. In addition, mouse body weight did not change significantly during the oligoarginine/siRNA treatment.

\section{口 LINEAR POLYAMIDOAMINES}

Poly(glycoamidoamine)s (PGAAs) were synthesized as efficient and degradable carriers by solution reaction. Hexosederived dicarboxylic acids were reacted with the terminal primary amines of defined protected oligoethylenimines under amide formation, followed by deprotection of the transient protected secondary amines of the polyamines. ${ }^{71,72}$

The PGAAs with four secondary amines with (D4, G4, M4, and T4) and analogues without (O4, S4, and A4) hydroxyl groups (Figure 4) within the dicarboxylic acid displayed differences in polymer degradation, pDNA complexation, toxicity, and transfection efficiency. Polymer degradation was facilitated through secondary amines and hydroxyls, which act as electron-withdrawing groups that formed hydrogen bonds. Degradation did not affect buffering capacity and was faster at $\mathrm{pH} 7.4$ than at $\mathrm{pH}$ 5. Polymer degradation showed no effect on cell survival, but did on polyplex stability. Nearly $100 \%$ of cells were positive for $\mathrm{Cy} 5$ when exposed to PGAA/Cy5-pDNA polyplexes, whereas G4/DNA polyplexes showed the highest fluorescence intensity. All secondary amine containing PGAA polyplexes, formed with pDNA, showed luciferase gene expression. In contrast, GO2, in which the secondary amines were substituted with ethylene oxide units, did not show pDNA binding or gene transfer. In the nonhydroxylated analogues, pDNA binding affinity was slightly influenced by the length of the dicarboxylic acid (A4 > S4 > O4). DNA affinity increased slightly with the length of the methylene spacer in the repeat unit of the polymer due to electrostatic, van der Waals, and hydrogen bonding forces. These forces could be strengthened by the increasing distance between the amide monomer linkers. A substantial contribution of hydrophobic interactions to the binding mechanism was not observed. Carbohydrate hydroxyl groups were not necessary for binding and compaction of pDNA, but they enhanced binding strength. The latter correlated with transfection efficiency. Gene expression also appeared to be driven by degradation of the polymeric vehicle. ${ }^{72}$ PGAAs were taken up via a complex, multifaceted internalization pathway. ${ }^{73}$

\section{SEQUENCE-DEFINED POLYAMIDOAMINES}

Solid phase peptide synthesis (SPPS) provided important technology such as orthogonal protective groups, which can be very useful also for synthesizing monodisperse sequence-defined polymers. ${ }^{30}$ Instead of applying only protected natural amino acids in SPPS, artificial monomer building blocks are introduced to precisely position various functionalities. Natural and nonnatural amino acids, but also monomers of completely different chemistries, chemical targeting ligands, PEG molecules, or lipophilic domains can be used as functionalities. Hartmann and Börner applied SPPS for the generation of sequence-defined multifunctional polyamidoamines. ${ }^{74-79}$ Alternate coupling steps of diacids (succinic anhydride, Suc) and diamines, such as diamino- $N$-methyldipropylamine (Damp) or $(t B o c)$-spermine (tBoc-Spe), led to stepwise assembly of polyamidoamines (Figure 5). ${ }^{78}$ Within the single-component PAA-block segment, functionalities were positioned precisely along the polymer, allowing local control of the chain properties. Addition of PEG to two different PAA block conjugates results in PEG-block-(SucSpe $)_{10}$ or PEG-block-(Suc-Damp) $)_{10}$-Suc polymer. ${ }^{77}$

For further determination of the correlation between chemical structures and biological properties, PEG-PAAs containing only tertiary amines (PEG-tPAA), tertiary and secondary amines (PEG - tpPAA), or secondary and primary amines (PEG-spPAA) were compared. ${ }^{76}$ Interestingly, various structures were observed when polyplexes were formed with double-stranded DNA: PEG-tPAA formed ring-like structures, and PEG-tpPAA formed multimeric bundles and rod-like structures, whereas for PEG-spPAA uniform single-plasmid toroids and supercoiled pDNA were observed. The pDNA complexation and condensation properties of the PAAs were strongly dependent on concentration, volume, and mixing rates. PEG stabilized the polyplex and simultaneously produced "stealth" aggregates, which led not only to stable singleplasmid complexes but stabilized the pDNA itself. Moreover, the $\mathrm{PEG}-t \mathrm{PAA} / \mathrm{DNA}$ polyplexes were more stable to DNase digestion than $\mathrm{PEG}-$ spPAA polyplexes due to the increased steric shielding. PEG - sp PAA stimulated cell activity to a small degree and showed no decrease of cell viability.

A bioreducible system with disulfide bonds stable in the oxidative surrounding of extracellular fluids was generated. This polyamidoamine-block-PEG with a single disulfide moiety was synthesized by the selective positioning of a cysteamine (Cya) into the polyamine backbone $\left(\mathrm{PEG}_{60}-\mathrm{Lys}\left(\mathrm{Suc}-\mathrm{Cya}-\mathrm{Lys}_{2}\right)-\right.$ $\left.(\text { Suc-Damp-Lys })_{4}\right)^{75}$ The disulfide bonds of this linear polymer can be degraded in the intracellular reductive environment of cells. Gel electrophoresis revealed the formation of stable pDNA-polyplexes with polyplex size around $160 \mathrm{~nm}$ and a zeta potential of 0 due to the steric shielding effects of PEG.

Boc-L-alanine was used as starting material for the synthesis of a chiral diamine building block ADN (Figure 5). ${ }^{79}$ The carboxylic 


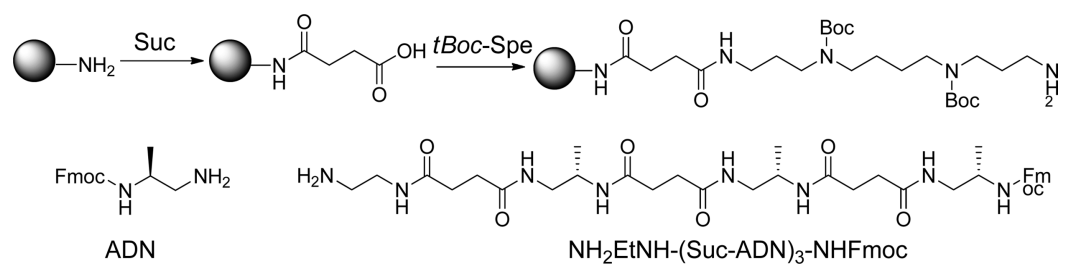

Figure 5. Alternate coupling steps of Suc and $t B o c$-Spe on solid phase and chrial building block ADN.

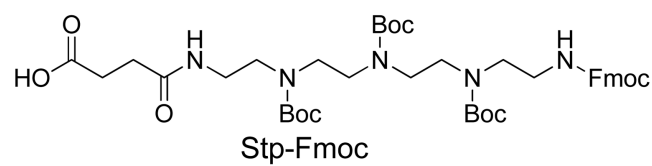

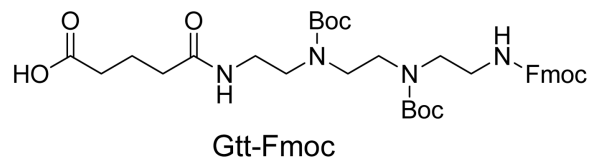<smiles>CCNCCN(CCN(CCN(CCNC(=O)OCc1ccccc1)C(=O)c1ccccc1)C(=O)c1ccccc1)C(=O)c1ccccc1</smiles><smiles>O=C(O)NCCN(CCN(CCN(CCNC(=O)c1ccccc1C(=O)O)C(=O)c1ccccc1)C(=O)c1ccccc1)C(=O)OCc1ccccc1</smiles>

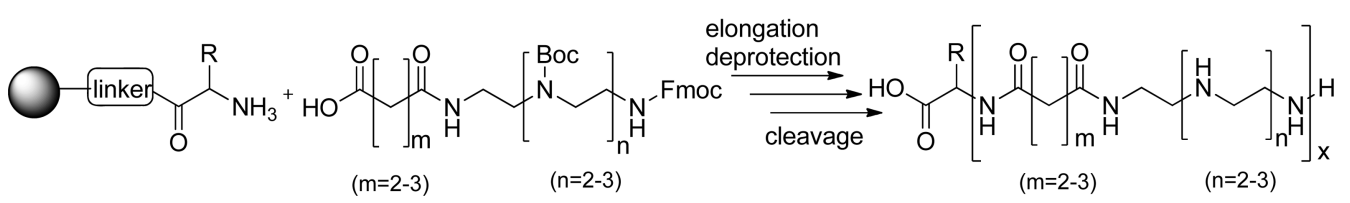

Figure 6. SPPS compatible building blocks and SPPS-based polymer assembly.

function of the $\alpha$-amino acid was reduced, and afterward the hydroxyl group was transformed into a methanesulfonate. After nucleophilic addition of an azide, the Boc protection group was removed, and the obtained hydrochloride salt of the amino solid phase peptide synthesis group was protected with Fmoc. The azide was reduced to an amine, resulting in the chiral building block ADN. The iterative coupling of succinic anhydride and this chiral diamine building block on the solid phase led to chiral Suc-ADN-block polymers (Figure 5), which are under further investigation.

As a variation of the concept, Schaffert et al. introduced novel Fmoc/Boc-protected polyamino acids (Stp, Gtp, Gtt, Ptp; Figure 6) fully compatible with standard Fmoc-peptide synthesis. ${ }^{80}$ The Fmoc-polyamino acids contain diacids as well as diamines in one building block. The secondary amines of tetraethylenepentamine (tp) or triethylenetetramine (tt) were protected with di-tertbutyl dicarbonate. The symmetrical Boc-protected diamines were monoacetylated in the first step with various cyclic anhydrides, succinic $(S)$, phthalic $(P)$, or glutaric $(G)$ anhydride, followed by subsequent Fmoc protection. The novel building blocks were assembled by standard Fmoc/Boc SPPS, optionally in combination with natural amino acids (Figure 6), to provide defined polycations. ${ }^{80}$ The presented strategy has recently been applied for the synthesis of a library of $>300$ defined polycationic carriers for nucleic acid delivery, including efficient pDNA and siRNA carriers. ${ }^{81}$ The artificial amino acids Stp, Gtp, and Gtt were applied together with lysines as branching units, cysteines as bioreversible disulfide forming units, and various fatty acids as domains providing hydrophobic stabilization but also endosomal membrane destabilization. As topology can influence biophysical and biological properties, branched polymers or linear polymers optionally with modification in the center ( $T$-shapes) or the end of chains (i-shapes, U-shapes) were designed and tested.<smiles>CCCCCCCCCCCCCCNC(=O)C(CS)NC(=O)C([NH3+])CCC[NH3+]</smiles>

Figure 7. Cationic detergent $\mathrm{C}_{14} \mathrm{CO}$.

\section{DEFINED LIPOPEPTIDES AND LIPOPOLYMERS (LIPOIDS)}

pDNA lipoplexes formed by complexation of pDNA with liposomes usually present rather large nanoparticles containing several pDNA molecules. For monomolecular condensation of pDNA into small particles of around $20-30 \mathrm{~nm}$, the group of J.-P. Behr designed cysteine-containing, amphiphilic, cationic detergents such as guanidinocysteine $\mathrm{N}$-decylamide ${ }^{82}$ or other thiol detergents with dodecane $\left(C_{12}\right)$, tetradecane $\left(C_{14}\right)$, or hexadecane $\left(\mathrm{C}_{16}\right)$ chains and spermine $(\mathrm{S})$ or ornithine $(\mathrm{O})$ headgroups ${ }^{83}$ (see Figure 7).

The detergents were selected to possess a rather high critical micelle concentration (CMC), well above the concentration applied in pDNA complexation, and form small reversible unimolecular pDNA complexes. Upon oxidization of cysteines, which is accelerated in the presence of template pDNA, the detergent dimers behave like lipids with low CMC, making the pDNA complex stable. The monodisperse particles in early investigations had a negative surface potential and could not transfect cells.

Addition of cyclic pentapeptide RGD (cRGDfK) to $\left(\mathrm{C}_{14} \mathrm{CO}\right)_{2}$ for targeting endothelial cells in $\alpha_{\mathrm{v}} \beta_{3}$ integrin-expressing primary endothelial cells resulted in the cRGDfK lipid. ${ }^{84}$ The helper lipid dioleoylphosphatidylethanolamine (DOPE) 


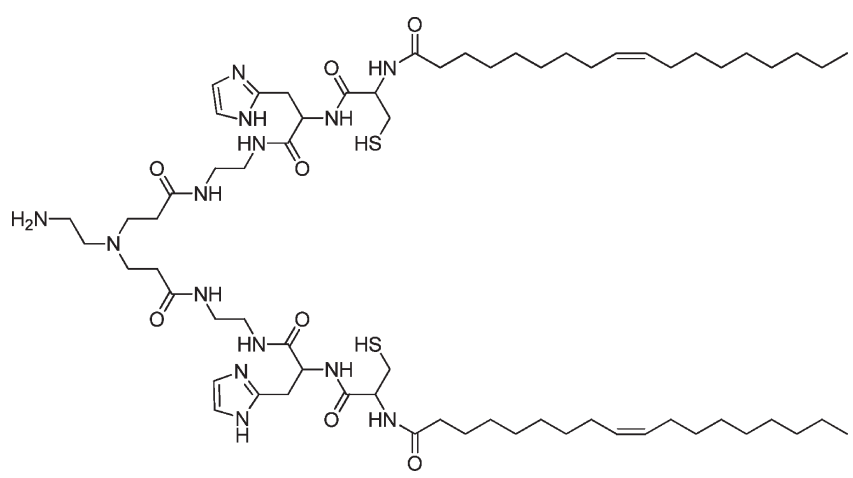

Figure 8. Amphiphilic siRNA vector EHCO.

was included to enhance the endosomolytic release. pDNA complexes containing the cRGDfK-lipid conjugate transfected more effectively than analogous nanoparticles containing a cRADfK-lipid control conjugate. Transfection was further increased by the addition of endosomal active chloroquine.

A further cationic detergent, built up of dodecanoic acid, cysteinyl-cysteine, and diaminopropane, formed $32 \mathrm{~nm}$ large, neutral DNA complexes, which were stable toward the exchange with extracellular polyanions. ${ }^{85}$ Pharmacokinetics and biodistribution in mice showed $25 \%$ of the complexes still circulating after 30 min due to small particle size and the stabilizing effect of the surface cross-linking.

$\mathrm{Lu}$ introduced ethylenediamine (E) and spermine-based elivery systems derived by SPPS, combining the artificial monomers with selected natural amino acids. ${ }^{86,87}$ Branching lysines, cross-linking cysteines, and oleic acid moieties were included in the polymers to form polyplexes with $\mathrm{pDNA}$ based on electrostatic and hydrophobic interactions, further stabilized by disulfide bond formation.

An ethylenediamine-containing, $\mathrm{pH}$-sensitive, amphiphilic multifunctional siRNA carrier EHCO (Figure 8) displayed high cellular siRNA delivery in vitro, as well as in vivo. ${ }^{88} \mathrm{EHCO}$ forms stable nanoparticles with siRNA. However, at doses required for in vivo administration, both EHCO and DOTAP control siRNA complexes were turbid, which made intraperitoneal (ip) injection necessary. Nevertheless, luciferase activity of subcutaneous U87Luc tumors could be silenced by ip EHCO (but not DOTAP) siRNA complexes by $>50 \%$. To possibly enhance bioavailability and render complexes suitable for intravenous administration, the EHCO polyplexes were modified with PEG. PEGylated $\mathrm{EHCO} /$ siRNA nanoparticles showed significantly lower luciferase gene silencing as compared to unmodified $\mathrm{EHCO} / \mathrm{siRNA}$ nanoparticles. ${ }^{89}$ For targeted delivery into tumor cells a RGD or bombesin (BN) peptide was attached to a PEG spacer with a maleimido (MAL) group, resulting in RGD-PEG-MAL or BN-PEG-MAL. The PEGylation of the surface thiol groups of EHCO-siRNA nanoparticles led to receptor-mediated uptake and high gene silencing efficiency. The systemic administration of targeted $\mathrm{EHCO} / \mathrm{siRNA}$ PEG conjugates resulted in a significantly slower tumor growth rate. The RGD-targeted delivery system was more effective than the bombesin-targeted system in tumor inhibition after the last injection.

From a new small screen, EKHCO and EHHKCO were selected as polymerizable, $\mathrm{pH}$-sensitive surfactants with nucleic acid binding capacity. ${ }^{87}$ Complete pDNA condensation took place already at low $\mathrm{N} / \mathrm{P}$ ratios, resulting in biologically inactive particles of 500-700 $\mathrm{nm}$. Doubling of the polymer amount reduced the size to $150-200 \mathrm{~nm}$. For complete siRNA condensation

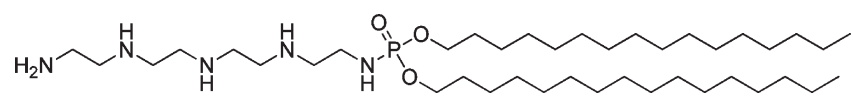

Figure 9. Dicetyl phosphate-tetraethylenepentamine.

a higher N/P ratio was necessary. Both the DNA and siRNA complexes of EHHKCO showed $\mathrm{pH}$ - and concentration-dependent hemolytic activity, whereas EKHCO had higher $\mathrm{pH}$ sensitivity. DNA and siRNA polyplexes exhibited a high intercellular uptake in U87, in additional to low cytotoxicity. GFP expression was observed in fewer than $10 \%$ of the cells, whereas luciferase knockdown resulted in 71.4 and $57.4 \%$ silencing effects with siRNA for EHHKCO and EKHCO, respectively.

The spermine (S)-based $\mathrm{pH}$-sensitive carriers had a protonable headgroup, followed by natural amino acids (alanine, histidine, lysine, serine, and cysteine) and a lipophilic oleic acid tail. ${ }^{86}$ Permutation of the natural amino acids resulted in several different gene delivery vectors, such as SKCO, SKHCO, SHKCO, SHHKCO, SKACO, SKAHCO, SHKACO, or SHHKACO. Polyplex sizes were around $100 \mathrm{~nm}(\mathrm{~N} / \mathrm{P}$ 12). The pDNA condensation ability and uptake were comparable to those of the ethylenediamine-based polymers. However, GFP expression was found in an increased number of the transfected cells, whereas SKACO was identified as a promising lead carrier with the highest activity.

Several papers demonstrate encouraging siRNA delivery by lipophilic modified oligoethylenimines. Philipp et al. modified low molecular weight OEI by Michael addition with different lipophilic acrylate esters. ${ }^{90}$ OEI-HA10, modified with 10 equiv of hexyl acrylate (HA), alone or in combination with the helper lipid DOPE, displayed high potency in siRNA-mediated gene silencing. Another related development for siRNA delivery, TEPA-polycationic liposomes (PCL), consists of dicetyl phosphate-tetraethylenepentamine (DCP-TEPA, Figure 9) and DOPE, dipalmitoylphosphatidylcholine, and cholesterol (Chol). ${ }^{91}$

The zeta potential of the TEPA-PCL was higher at low $\mathrm{pH}$ values than in the neutral $\mathrm{pH}$, due to the increased protonation of the polycation. No cytotoxicity and highest GFP knockdown were observed at N/P ratios of 18 or 24. TEPA-PCL modified with PEG 2000 altered biodistribution and avoided reticuloendothelial system (RES) uptake. Moreover, the long-term circulation was increased. Unfortunately, free siRNA was detected after gel electrophoresis of the PEGylated TEPA-PCL/siRNA polyplexes. Thus, the siRNA was covalently attached to cholesterol at the $3^{\prime}$-position of the sense strand (PEG-TEPA-PCL/siRNAChol). Additionally, the Ala-Pro-Arg-Pro-Gly peptide was used as ligand for angiogenic vessels. ${ }^{92}$ In vivo imaging resulted in an APRPG-TEPA-PCL/siRNA-Chol fluorescent signal in the whole body and accumulations in the bladder, liver, and tumor.

For gemini-like peptides, so-called geminoids, the amino acids serine $(S)$, proline $(P)$, lysine $(K)$, and arginine $(R)$ were assembled on solid phase and further modified with oleyl or oleoyl alkyl chains. ${ }^{93}$ Proline and at least one cationic residue, either arginine or lysine, were necessary for the biological activity. The synthesized alanine derivatives were mutants in this setup, to investigate the importance of the single amino acids. 1-SPKR, a geminoid with two unsaturated $\mathrm{C}_{18}$-alkyl chains, formed particles with diameters around $100 \mathrm{~nm}$ and bound pDNA completely. The transfection efficiency depended on the geminoid and DNA amount. 2-SPKR, a construct in which 1-octadecylamine was used instead of oleylamine and stearic acid instead of oleic acid, 

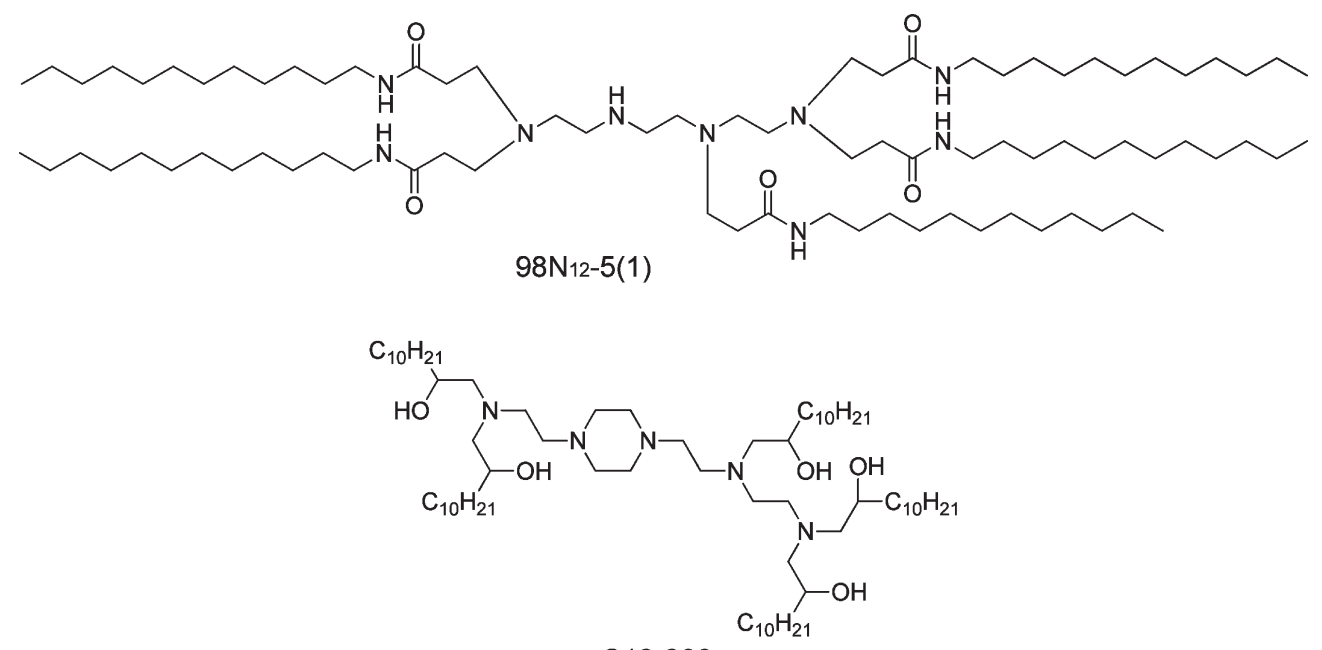

C12-200

Figure 10. Lipidoids for nucleic acid transport.

was inefficient in HeLa cell transfection. Complexes of 1-SPKR and 1-APKR with anti-GFP-specific siRNA showed a knockdown, whereas no toxicity was observed when transfected with control siRNA.

A number of parameters were varied in a combinatorial library of lipidoids, which was synthesized through the addition of alkyl acrylates or alkyl acrylamides to primary or secondary amines. ${ }^{94}$ Some structural prerequisites for efficient siRNA or micro RNA delivery were necessary: $8-12$ carbons in the tail, $>2$ alkyl chain, amide linkages, and at least one secondary amine. All lipidoids, inducing gene silencing, displayed low cytotoxicity in different cell lines. One of the best performers, $98 \mathrm{~N}_{12}-5(1)$ (Figure 10), consisted of a tetraethylenepentamine core with five dodecylates. Based on a three-component delivery system containing this lipoid $98 \mathrm{~N}_{12}-5(1)$, cholesterol, and the PEG lipid $\mathrm{mPEG}_{2000^{-}}$ C14 glyceride, a combinatorial approach was used to incorporate further diversities into this promising siRNA delivery candidate. ${ }^{95}$ The new library of carriers was based on lipid-like tails with hydroxyl, carbamate, ether, or amine functional groups, attached to two different cores, 98 and $100 .^{96}$ The amine cores were modified by the addition of different arcylamides and acrylates. The luciferase expression was tested in HeLa cells at different weight to weight ratios. The knockdown at a w/w ratio of 15 (lipidoid: siRNA) was highest, whereas the efficiency decreased with decreasing ratios of lipidoids to siRNA. The efficacy of both amine cores was affected by tail modifications: core 100 was more efficient in silencing and more tolerant to the addition of the functional groups. Tails functionalized with ether, carbamate, or amine groups were most active. Only 4 of 17 lipidoids containing core 98 were effective, compared to 14 of 17 for core 100 . PEG or long alkyl chains containing lipidoids were inactive, no matter to which core they were attached. The addition of a tertiary amine reduced the effectiveness specifically for core 98 . All compounds had at least one $\mathrm{w} / \mathrm{w}$ ratio for which the cell viability was $>80 \%$. Nevertheless, three active formulations of core 98 and one of core 100 had a viability of $<60 \%$. For improved serum stability the siRNA-containing lipidoids were mixed with cholesterol and PEG-ceramide. The in vivo efficacy was tested by a factor VII knockdown, and all tested derivates showed a decrease in factor VII serum levels, whereas all core 98 formulations were more effective than core 100 formulations.
Love et al. used a related combinatorial approach for the synthesis and screening of a library of oligonucleotide delivery systems. ${ }^{97}$ This library consisted of nondegradable amino alcohols based on a polar amine-containing headgroup and a nonpolar hydrocarbon tail. Synthesis was achieved through the ringopening of epoxides by amine substrates. The reaction was carried out without solvents, protection and deprotection steps, or further purification and was therefore well suited for the parallel synthesis approach and high-throughput screening. As a prerequisite for a knockdown at least 12 carbons in length was needed in the lipidoid tail.

To monitor the lipidoid-facilitated siRNA delivery, the mouse factor VII gene silencing model was used. To improve serum stability lipidoids were formulated with distearoylphosphatidylcholine, cholesterol, and PEG. After a single bolus administration, C12-200, the most promising candidate (Figure 10), resulted in reduced factor VII serum levels without observable toxicity. A simultaneous silencing of up to five genes was possible with C12-200. Additionally, C12-200-mediated silencing was investigated in nonhuman primates and siRNA specific to transthyretin (TTR). Dosing nonhuman primates with C12-200-TTR siRNA resulted in high levels of specific knockdown. ${ }^{97}$

\section{- FUNCTIONAL POLYMER CONJUGATES}

A plain polymer, even when optimized and modified with lipid domains, may not be the perfect carrier for overcoming all delivery steps. Conjugation of additional natural or artificial biomimetic transport functions such as cell targeting ligands may further improve a carrier. A high percentage of human carcinomas overexpress the epidermal growth factor receptor (EGFR). LPEI, PEG-LPEI, and EGF-PEG-bPEI pDNA polyplexes were evaluated as synthetic gene vectors. ${ }^{98}$ EGFR targeting led to a faster and more efficient internalization as compared to the untargeted LPEI and PEG-PEI pDNA nanoparticles. To facilitate the release of the polyplexes from the endosome into the cytosol, melittin (Mel), a bee venom peptide, was incorporated. ${ }^{29}$ Moreover, polyinosine-cytosine (polyIC) was used as an antiproliferative double-stranded RNA. Melittin was either complexed with the nucleic acid as PEI-Mel conjugate together with EGF-PEG-bPEI or covalently attached, 
Scheme 1. Cu(I)-Catalyzed 1,3-Dipolar Cycloaddition Reaction

$$
\mathrm{R}_{1}-\mathrm{N}_{3}+\equiv \mathrm{R}_{2} \stackrel{\mathrm{Cu}(\mathrm{I})}{\longrightarrow} \mathrm{R}_{1}-\mathrm{N}_{\mathrm{R}_{2}}^{\mathrm{N}=\mathrm{N}}
$$

resulting in EGF-PEG-bPEI-Mel. Both melittin dsRNA conjugates released their payload polyIC into the cytosol, whereas polyIC/EGF-PEG-bPEI complexes were entrapped within vesicles. The EGF-PEG-bPEI-Mel conjugate demonstrated enhanced transfection efficiency in vitro and in vivo, as compared to all other polyplexes. The applied tetraconjugate, however, was very complex and chemically not well-defined. To make it more practical, branched PEI was substituted with linear PEI, and the chain length of PEG was optimized to $2 \mathrm{kDa}$, resulting in a EGF-PEG-LPEI conjugate that was most effective in polyIC-triggered killing of tumor cells, even in the absence of melittin. ${ }^{99}$ Repeated intravenous injection of the more defined EGF-PEG-LPEI polyIC polyplex retarded tumor growth at least as effectively as the more heterogeneous EGFPEG-bPEI-Mel polyplex.

More defined LPEI conjugates were obtained through sitespecific coupling. ${ }^{100}$ Linear PEI was terminated at one end by a highly nucleophilic hydrazine residue. The $\omega$-regioselective conjugation to other molecules was possible through stable linkages. Transferrin was oxidized to obtain an aldehyde function and conjugated to hydrazino PEI. The resulting PEI-Tf vector had the targeting sequence precisely attached at one end. This precise conjugation technique and the resulting conjugates make structure-activity relationships possible.

\section{PRECISE CONJUGATION TECHNIQUES}

A series of "click chemistry" conjugation techniques have become available, ${ }^{101-104}$ which can be very useful for precise conjugation at selected sites of macromolecules (Scheme 1). As a variation of the Huisgen 1,3-dipolar cycloaddition, the $\mathrm{Cu}(\mathrm{I})$ catalyzed cycloaddition of terminal alkynes and azides $(\mathrm{CuAAC})^{105-107}$ proceeds efficiently and selectively under aqueous reaction conditions and in the presence of various other functionalities or biomolecules. ${ }^{108,109}$

Click chemistry is also fully compatible with the reaction conditions used for solid phase synthesis, in the synthesis of peptides and for modification of oligonucleotides. Copper-free click chemistries were even performed in living organisms. ${ }^{110}$ Several applications for polymer polymerizations and conjugations for nucleic acid delivery have been reported. ${ }^{111-116}$

Lee et al. modified different cores with PAMAM dendrimers via click chemistry using a stitching method for the synthesis of dendrimers and di-block dendrimers. ${ }^{117}$ The cycloaddition reaction took place between alkyne-functionalized PAMAM dendrons (1-Dm) and a multi(azides) building block as core unit. ${ }^{118}$ The resulting emissive PAMAM dendrimers had 2,7-diazido- $9 H$ fluorene as core chromophore.

Yu et al. applied click chemistry to introduce an EGF-PEG targeting group in a site-specific manner into PAMAMpentaethylenehexamine (PEHA) dendrons. ${ }^{119}$ As the coppercatalyzed chemistry is not compatible with copper-chelating oligoethylenimines, the click reaction with a bifunctional PEG derivative had to be performed using the PAMAM ester precursor, before introduction of the PEHA groups and EGF.
Alternative novel PAMAM polymer conjugation concepts are based on copper-free click chemistries. ${ }^{120}$

Copper-assisted or copper-free click chemistry can also be used for the synthesis of siRNA conjugates. ${ }^{121}$ Three possible synthesis routes were followed in CuAAC-mediated oligoribonucleotide-ligand conjugate synthesis: (i) The reaction took place at the monomer level prior to oligonucleotide synthesis, (ii) the solution phase postsynthetic "click conjugation" or (iii) the "click conjugation" on an immobilized and completely protected alkyne-oligonucleotide scaffold. ${ }^{122}$ The last approach was the most efficient one. The ligand was introduced to a desired site within the oligonucleotide sequence, at selected positions on the sugar moiety $\left(2^{\prime}-\right.$-, $3^{\prime}$-, or $5^{\prime}$-position $)$ or at selected sites of the nucleobase. Azido-functionalized ligands bearing oligoamines, long lipophilic alkyl chains, and cholesterol were used to study the effect of physicochemical characteristics of the incoming azide on click conjugation to the alkyne-oligonucleotide scaffold in solution and on an immobilized solid support. The hydrophobic and cationic azides reacted with oligonucleotide-alkynes, which were attached to the solid support. Those siRNA conjugates effectively silenced luciferase gene expression with addition of lipofectamine 2000 in a stably transformed HeLa cell line. Interestingly, the siRNA activity was not hampered by the insertion of an extra modified nucleotide to the $5^{\prime}$-end of the sense strand, in contrast to the addition of a bulky nucleotide at the $3^{\prime}$-end of the sense strand, which was not well tolerated.

Another conjugation technique is native chemical ligation (NCL, Scheme 2). Native chemical ligation was originally developed to connect two unprotected peptides for the total synthesis of proteins. ${ }^{123}$ An amide bond is formed by transthioesterification followed by intramolecular nucleophilic rearrangement between thioester and cysteine.

The chemoselective reaction occurs in mild aqueous solution, is simple, and gives almost quantitative yields. Byun attached cysteine-PEG to a titanium surface with thioester-containing phosphonic acid conjugates. ${ }^{124}$ This approach indicates the usefulness of NCL as a toolkit for surface bioconjugation and functionalization. The potential of NCL in the synthesis of precise polymers or conjugates for nucleic acid delivery has to be investigated further.

\section{DYNAMIC CONJUGATES}

PEG shielding was found to improve polyplex stability and reduce nonspecific interactions, but stable, irreversible PEGylation drastically reduced transfection efficiency. To overcome this obstacle, the PEG functionality was incorporated into conjugates in a dynamic fashion, to be cleaved in the acidic environment of endosomes but remaining stable at extracellular physiological $\mathrm{pH}$. Dynamic PEGylation of polymers was evaluated using various bioresponsive linkers. ${ }^{125-128}$ For example, various $\mathrm{pH}$ sensitive PEG hydrazones (HZN) were conjugated to poly-Llysine. ${ }^{125}$ The resulting PLL-HZN-PEG was then complexed with pDNA and Tf-PEI or EGF-PEI, conjugates containing a targeting receptor with endosomal uptake capacity. The in vitro transfection efficiency of those targeted, bioreversibly shielded polyplexes was up to $>100$-fold higher than those of the stably shielded polyplexes, similar to controls without shielding, and showed improved transfection to target tumor cells after intravenous application in vivo.

Amine-reactive PEG reagents, monofunctional PEG-HZN $\mathrm{N}$-hydroxysuccinimide ester (NHS) and bifunctional 
Scheme 2. Native Chemical Ligation<smiles>[R]C(=O)CCC(=O)SCCC(=O)OCC</smiles><smiles>C=POC(OC(=O)OCC)c1ccc(N2CCN(C(=O)CCN3C(=O)C=CC3=O)CC2)cc1</smiles><smiles>CCCOCCCC=NNc1ccc(C(=O)ON2C(=O)CCC2=O)cn1</smiles>

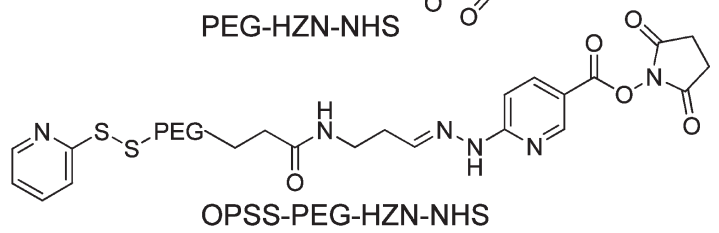<smiles>CC(=O)OCCOC(=O)CCC1=C(C)C(=O)OC1=O</smiles><smiles>CC(=O)N[C@@H]1[C@H](O)[C@H](O)[C@@H](CO)O[C@H]1OCCOCCNC(=O)CCC1=C(C)C(=O)OC1=O</smiles>

Figure 11. Monofunctional and bifunctional $\mathrm{pH}$-sensitive bioreversible PEGylation reagents.

OPSS-PEG-HZN-NHS (Figure 11), were synthesized for post-PEGylation of bPEI and LPEI. ${ }^{127}$ The heterobifunctional OPSS conjugate made a simultaneous PEGylation and incorporation of a targeting ligand possible. The targeting ligand EGF-PEG-bPEI was added to the PEG-HZN-NHS PEIDNA polyplex. The EGF-containing, bioreducible polyplexes had improved transfection activity compared to polyplexes with stable PEGylation using PEG-NHS instead of PEG-HZNNHS. Additionally, the labile PEG-HZN-NHS enhanced the efficiency of transgene delivery to distant tumor tissues with high specificity, even higher than pre-PEGylated polyplexes as described by Walker et al. ${ }^{125}$

The bifunctional, endosomal pH-cleavable reagent OPSSPEG-HZN was further modified with cholesterol. ${ }^{129}$ Both OPSS-PEG-HZN-Chol and its corresponding stable analogue OPSS-PEG-Chol spontaneously formed stable and shielded micelles at physiological $\mathrm{pH}$. Lipopolyplexes composed of DNA complexed with LPEI, phospholipids including DOPE, and OPSS-PEG-HZN-Chol displayed an enhancement of gene expression compared to lipopolyplexes with stable PEG conjugates, without visible toxicity. After incorporation of B6, a peptidic ligand for the transferrin receptor, further improvement in transfection efficiency was observed for the acid-labile lipopolyplexes.
Dialkylated maleic acid anhydrides react with amines under ring-opening to form monoamides. These maleamates, however, are cleaved again at slightly acidic conditions, such as the endosomal $\mathrm{pH}$ due to steric strain. To exploit this for $\mathrm{pH}$-reversible bioconjugation, Rozema and colleagues developed carboxylated forms of dimethylmaleic anhydride (CDM) and used them in CDM-PEG and related reagents. ${ }^{128}$

\section{COVALENT NUCLEIC ACID CONJUGATES}

The first polymer-oligonucleotide conjugates were prepared already more than 20 years ago. ${ }^{130}$ The first paper, developing the concept of bioreversible covalent conjugates of bioresponsive polymers with antisense oligonucleotides, was published by the Hoffman and Stayton laboratory. ${ }^{131,132}$ Asialoglycoprotein (ASGP) receptor targeted lactosylated and PEGylated antisense ODNs were developed for hepatocyte targeting. ${ }^{133}$ For sigmareceptor targeting of cancer cells, splice switching antisense ODNs were covalently attached with mono- or multivalent anisamide ligands. ${ }^{134}$ The trivalent anisamide-ODN conjugate displayed enhanced cellular uptake and higher efficacy than the monovalent conjugate in a luciferase reporter assay in tumor cell culture. An excellent overview of solid phase derived oligonucleotide conjugates is given by Lönnberg. 135

siRNA Conjugates. For the synthesis of covalent siRNA conjugates (reviewed by Jeong et al. ${ }^{136}$ ) the four terminal ends are potential conjugation sites: the $3^{\prime}$ - and $5^{\prime}$-ends of sense and antisense strand. The integrity of the $5^{\prime}$-terminus of the antisense strand plays an important role in the maintenance of the biological activity. Therefore, conjugation via cleavable linkers including acid-labile and reducible bonds is an elegant way to preserve the functionality of the siRNA. The chemical modifications, such as phosphorothioate, boranophosphate linkage, or modification of $2^{\prime}$-hydroxyl group of pentone sugar, enhance the stability of siRNA in biological fluids. ${ }^{136}$

Folate was evaluated as a ligand for siRNA delivery, with siRNA covalently bound via a linker resulting in enhanced intracellular uptake. ${ }^{137}$ Conjugation of cholesterol to an apolipoprotein B siRNA (apoB siRNA) led to a lipophilic siRNA conjugate. ${ }^{138}$ Cholesterol was attached to the $3^{\prime}$-terminus of the sense strand of siRNA by a pyrrolidone linker. The resulting Chol-apoB siRNA conjugate was biologically active, in contrast to unconjugated apoB siRNA. After systemic administration of Chol-apoB siRNA in vivo, an inhibition of apolipoprotein B was achieved by an RNAi mechanism of action. Nishina synthesized an $\alpha$ tocopherol (vitamin E)-siRNA for systemic siRNA delivery to the liver. ${ }^{139}$ Vitamin E was covalently attached to the 5 '-terminus of the antisense strand of a 27/29mer siRNA, partially modified with 2'-O-methylated ribose and phosphorothioate linkages. After intracellular delivery, the lipophilic siRNA conjugate was processed in the dicer and the vitamin E moiety was released. This conjugate led to a significant reduction of the target gene apolipoprotein B after intravenous injection without inducing inflammatory interferons. 


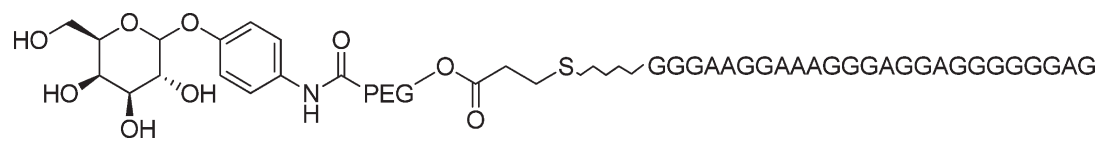

Figure 12. Covalent PEG-ODN conjugate with targeting ligand (Gal-PEG-ODN).

PEG Nucleic Acid Conjugates. Several publications report the covalent conjugation of siRNAs with PEG to improve pharmacological properties. ${ }^{128,133,140-143}$ For example, PEG was attached via the cleavable disulfide linkage SPDP to the $3^{\prime}$ terminus of the sense strand of a vascular endothelial growth factor (VEGF) siRNA. ${ }^{140}$ The resulting PEG-siRNA conjugate formed polyelectrolyte complex (PEC) micelles by interaction with the cationic PEI, as core forming agent. PEG-VEGF siRNA/PEI PEC micelles displayed high levels of serum stability over $48 \mathrm{~h}$, whereas PEG-VEGF siRNA or naked siRNA was less stable. Prolonged circulation, prevention of aggregation, and blood compatibility were results of the PEG modification. The intact VEGF-siRNA was released from the conjugate under reductive conditions. Consequently, an effective silencing of VEGF gene expression in prostate carcinoma cells was observed for PEG-VEGF siRNA/PEI PEC micelles under optimized formulation conditions. Moreover, PEC micelles led to a far superior silencing than VEGF siRNA/PEI complexes in the presence of serum, demonstrating the crucial role of PEG for the application.

A sugar-modified PEG-siRNA conjugate containing the disaccharide lactose ( $\mathrm{Lac}$ ), which is derived from the condensation of galactose and glucose, was introduced by Oishi. ${ }^{142}$ The siRNA was conjugated with lactosylated PEG through acid-labile linkage of thiopropionate, resulting in Lac-PEG-siRNA. Michael addition of the 5'-thiol-modified sense RNA with Lac-PEG gave a Lac-PEG conjugate with single-stranded RNA, which was then annealed with antisense RNA to undergo hybridization. Afterward, the Lac-PEG-siRNA was complexed with poly-Llysine (PLL) with a polymerization degree of 40, leading to a quantitative complexation at the charge ratio of 1 . Those PEGbased block ionomers self-assembled to lactosylated-polyion complex (PIC) micelles, which showed $\mathrm{pH}$-sensitive dissolution properties. PEG-block-polycation/oligonucleotides, as well as PEG-block-oligonucleotide/polycation conjugates or PEGoligonucleotide conjugate/polycation conjugates, were feasible for PIC micelle formulation. The PIC core was surrounded by PEG layers to increase biocompatibility and enzymatic tolerability. PIC micelles formed with Lac-PEG-siRNA/PLL were more effective, regarding silencing of the target gene in $\mathrm{HUH}-7$ cells, compared to Lac-PEG-siRNA conjugates. Both conjugates exhibit RNA interference (RNAi) activities in a dosedependent manner, even in the presence of serum.

For enhanced site-specific ASGP-receptor-mediated hepatocyte targeting with a covalently bound polycation, Zhu et al. conjugated galactosylated (Gal) PEG to ODN with an acid-labile $\beta$-thiopropionate ester linkage. ${ }^{143}$

After tail vein injection into rats, the Gal-PEG-ODN (Figure 12) was rapidly cleared from the circulation and accumulated in the liver.

Additionally, Zhu et al. evaluated two different targeting ligands in liver-targeted PEG-siRNA conjugates: galactose for ASGPR-mediated hepatocyte targeting and mannose-6-phosphate (M6P) for hepatic stellate cells. ${ }^{133}$ The sugars attached to PEG, containing the acid labile ester linker OPSS, were coupled to the sense strand of luciferase and transforming growth factor $\beta 1$ (TGF- $\beta 1$ ) siRNA. The functionality of the cleavable disulfide linker was investigated for both conjugates: When treated with dithiotreitol, the siRNA dissociated from the Gal/ M6P-PEG-siRNA conjugates. The conjugates containing siRNA targeting firefly luciferase showed gene silencing. Even higher gene silencing was observed for the same siRNA amount when the conjugates formed complexes with pyridinium cationic liposomes. TGF- $\beta 1-$ siRNA with Gal-PEG and M6P-PEG silenced endogenous TGF- $\beta 1$ gene expression comparably to the firefly luciferase conjugates without the cationic liposomes.

PEG-Polymer-siRNA Conjugates. A pH-sensitive reversible PEG reagent (CDM-PEG, Figure 11) was used in the formation of a hepatocyte-targeted polymer siRNA conjugate. ${ }^{128}$ CDM-PEG was attached to the endosomolytic carrier polymer PBAVE, an amphipathic poly(vinyl ether) composed of butyl and amino vinyl ethers. The bifunctional maleamate linkage between PBAVE and the shielding agent PEG is reversible at endosomal $\mathrm{pH}$. A CDM linker was also used for conjugating the polymer with $\mathrm{N}$-acetylgalactosamine (NAG), an amino sugar derivative of galactose recognized by the asialoglycoprotein receptor of hepatocytes. The siRNA cargo was coupled to the PEG-PBAVE-NAG via a reversible disulfide linker, resulting in siRNA dynamic polyconjugates. Key features of these polyconjugates were a membrane active polymer, the ability to reversibly mask the activity of the polymer until it reached the acidic environment of endosomes, and the ability to target this polymer and its siRNA cargo specifically to hepatocytes in vivo. An effective knockdown of two endogenous genes in the mouse liver, with phenotype changes in vivo, was observable for 7-10 days. Therefore, two different siRNAs were used in the polyconjugates, one silencing apolipoprotein $\mathrm{B}$ and the other one silencing peroxisome proliferator-activated receptor $\alpha$ (ppar $\alpha$ ). Both conjugates targeted hepatocytes and avoided Kupffer cell uptake, resulting in no observable liver toxicity. Moreover, they were well tolerated. The apoB-siRNA dynamic polyconjugates led to a knockdown of $80-90 \%$ of apoB in vivo and, additionally, to lowered serum cholesterol and apoB protein levels, as well as a fatty liver. Readministration reduced serum cholesterol levels a second time. Mice treated with siRNA polyconjugates targeting ppar $\alpha$ also displayed the gene-appropriate phenotype, characterized by a significant increase in serum triglycerides. Substitution of NAG with mannose resulted in redirection of the polyconjugate to nonparenchymal liver cells, away from hepatocytes.

DMMAn-Mel is an endosomolytic agent in which the lytic peptide melittin is masked by reaction with dimethyl maleic anhydride (DMMAn), a noncarboxylated analogue of CDM. The DMMAn group is removed at acidic $\mathrm{pH}$ and functional melittin is displayed, liberating the payload from the endosome. ${ }^{144,145}$ A PLL-based dual responsive, that is, $\mathrm{pH}$ - and redox-responsive, polymer conjugate was developed. ${ }^{141}$ PEG contributes to the conjugate solubility and shields the polymer. The siRNA was attached to the PEG-PLL-DMMAn-Mel at the 5 -terminus via a bioreducible disulfide bond. The conjugate was stable in the 
presence of the polyanion heparin at conditions under which analogous electrostatic siRNA complexes disassembled. The $\mathrm{pH}$ triggered, lytic activity of the conjugate was verified in an erythrocyte leakage assay; thus, it showed high in vitro biocompatibility due to the absence of cytotoxicity or hemolytic activity at neutral $\mathrm{pH}$. Reduction, by low physiological concentrations of glutathione, resulted in the release of siRNA from the carrier conjugate. Moreover, an efficient and sequence-specific luciferase gene silencing was found for the PEG-PLL-DMMAnMel-siRNA conjugate comparable to the corresponding electrostatic polyplexes in Neuro2A-eGFPLuc cells. Unfortunately, the particular conjugate, based on a rather high molecular weight PLL (DP 153), displayed an unexpected high in vivo toxicity, requiring further optimization. ${ }^{141}$

\section{CONCLUSION}

In recent years, considerable progress has been made in discovering conditions and structural features that are required for nucleic acid transfer into mammalian cells. Precise polymers or conjugates are expected to play an important role in further refining structure-activity relationships. The ability of precise synthesis allows analysis of the influence of the conjugation site, single amino acids, or lipophilic domains in the polymer sequence. Up to now, PAMAM dendrimers have been the most promising precise polymers efficient in nucleic acid delivery. Solid phase supported peptide synthesis is an elegant tool for obtaining precise polymer conjugates. The concept has been extended to the synthesis of sequence-defined polyamidoamines, which, when properly modified, present very promising nucleic acid carriers. For example, lipophilic modifications play an important role in the carrier activity of lipopolymers. Several lipidoids, coformulated with cholesterol and PEG lipids, were already successfully applied for in vivo application of siRNA. Techniques such as click chemistry or native chemical ligation have great potential for the synthesis of precise conjugates of polymers with functional domains and nucleic acids. The application of these methods with precise polymers will provide exciting insights in structure-activity relationships of delivery systems and will be instrumental for the preparation of optimized clinically applicable delivery systems.

\section{AUTHOR INFORMATION}

\section{Corresponding Author}

*Phone: +49 892180 77841. Fax: +49 892180 77798; E-mail: ernst.wagner@cup.uni-muenchen.de.

\section{ACKNOWLEDGMENT}

Funding of the authors' work in the reviewed research area by the Cluster of Excellence "Nanosystems Initiative Munich" of the German Research Foundation and the BMBF Biotech cluster $\mathrm{m} 4$ project $\mathrm{T} 12$ is gratefully acknowledged.

\section{ABBREVIATIONS}

B6 peptide, Ac-CGHKAKGPRK-NH ${ }_{2}$; Boc, tert-butoxycarbonyl; CDM, carboxy dimethyl maleic anhydride; DPL, dendritic polylysine; Fmoc, 9-fluorenyl methoxycarbonyl; GFP, green fluorescent protein; OEI, oligoethylenimine; OPSS, $\omega$-2-pyridyldithio; pbf, 2,2,4,6,7-pentamethyldihydrobenzofuran-5-sulfonyl;
PEG, polyethylene glycol; SPDP, N-succinimidyl 3-[2-pyridyldithio]-propionate; TFA, trifluoroacetic acetate; trt, trityl.

\section{REFERENCES}

(1) Gao, K., and Huang, L. (2008) Nonviral methods for siRNA delivery. Mol. Pharmaceutics 6, 651-658.

(2) Lin, C., Blaauboer, C.-J., Timoneda, M. M., Lok, M. C., van Steenbergen, M., Hennink, W. E., Zhong, Z., Feijen, J., and Engbersen, J. F. J. (2008) Bioreducible poly(amido amine)s with oligoamine side chains: synthesis, characterization, and structural effects on gene delivery. J. Controlled Release 126, 166-174.

(3) Schaffert, D., and Wagner, E. (2008) Gene therapy progress and prospects: synthetic polymer-based systems. Gene Ther. 15, 1131-1138.

(4) Wolff, J. A., and Rozema, D. B. (2008) Breaking the bonds: nonviral vectors become chemically dynamic. Mol. Ther. 16, 8-15.

(5) Wagner, E. (2004) Strategies to improve DNA polyplexes for in vivo gene transfer: will "artificial viruses" be the answer? Pharm. Res. $21,8-14$.

(6) Wagner, E. (2008) Converging paths of viral and non-viral vector engineering. Mol. Ther. 16, 1-2.

(7) Wagner, E., Plank, C., Zatloukal, K., Cotten, M., and Birnstiel, M. L. (1992) Influenza virus hemagglutinin HA-2 N-terminal fusogenic peptides augment gene transfer by transferrin- polylysine-DNA complexes: toward a synthetic virus-like gene-transfer vehicle. Proc. Natl. Acad. Sci. U.S.A. 89, 7934-7938.

(8) Zuber, G., Dauty, E., Nothisen, M., Belguise, P., and Behr, J. P. (2001) Towards synthetic viruses. Adv. Drug Deliv. Rev. 52, 245-253.

(9) Krebs, M. D., and Alsberg, E. (2011) Localized, targeted, and sustained siRNA delivery. Chemistry 17, 3054-3062.

(10) Mintzer, M. A., and Simanek, E. E. (2009) Nonviral vectors for gene delivery. Chem. Rev. 109, 259-302.

(11) Dekie, L., Toncheva, V., Dubruel, P., Schacht, E. H., Barrett, L., and Seymour, L. W. (2000) Poly-L-glutamic acid derivatives as vectors for gene therapy. J. Controlled Release 65, 187-202.

(12) Burke, R. S., and Pun, S. H. (2008) Extracellular barriers to in vivo PEI and PEGylated PEI polyplex-mediated gene delivery to the liver. Bioconjugate Chem. 19, 693-704.

(13) Chen, H. H., Ho, Y.-P., Jiang, X., Mao, H.-Q., Wang, T.-H., and Leong, K. W. (2008) Quantitative comparison of intracellular unpacking kinetics of polyplexes by a model constructed from quantum Dot-FRET. Mol. Ther. 16, 324-332.

(14) Midoux, P., Breuzard, G., Gomez, J. P., and Pichon, C. (2008) Polymer-based gene delivery: a current review on the uptake and intracellular trafficking of polyplexes. Curr. Gene Ther. 8, 335-352.

(15) Nishiyama, N., Arnida, Jang, W.-D., Date, K., Miyata, K., and Kataoka, K. (2006) Photochemical enhancement of transgene expression by polymeric micelles incorporating plasmid DNA and dendrimerbased photosensitizer. J. Drug Targeting 14, 413-424.

(16) Grosse, S., Thévenot, G., Monsigny, M., and Fajac, I. (2006) Which mechanism for nuclear import of plasmid DNA complexed with polyethylenimine derivatives? J. Gene Med. 8, 845-851.

(17) Parker, A. L., Newman, C., Briggs, S., Seymour, L., and Sheridan, P. J. (2003) Nonviral gene delivery: techniques and implications for molecular medicine. Expert Rev. Mol. Med. 5, 1-15.

(18) Christie, R. J., Nishiyama, N., and Kataoka, K. (2010) Minireview: Delivering the code: polyplex carriers for deoxyribonucleic acid and ribonucleic acid interference therapies. Endocrinology 151, 466-473.

(19) Kunath, K., von Harpe, A., Fischer, D., Petersen, H., Bickel, U., Voigt, K., and Kissel, T. (2003) Low-molecular-weight polyethylenimine as a non-viral vector for DNA delivery: comparison of physicochemical properties, transfection efficiency and in vivo distribution with highmolecular-weight polyethylenimine. J. Controled Release 89, 113-125.

(20) Itaka, K., Harada, A., Yamasaki, Y., Nakamura, K., Kawaguchi, H., and Kataoka, K. (2004) In situ single cell observation by fluorescence resonance energy transfer reveals fast intra-cytoplasmic delivery and easy 
release of plasmid DNA complexed with linear polyethylenimine. J. Gene Med. 6, 76-84.

(21) Kichler, A., Leborgne, C., Coeytaux, E., and Danos, O. (2001) Polyethylenimine-mediated gene delivery: a mechanistic study. J. Gene Med. 3, 135-144.

(22) Sonawane, N. D., Szoka, F. C., Jr., and Verkman, A. S. (2003) Chloride accumulation and swelling in endosomes enhances DNA transfer by polyamine-DNA polyplexes. J. Biol. Chem. 278, 4482644831.

(23) Akinc, A., Thomas, M., Klibanov, A. M., and Langer, R. (2005) Exploring polyethylenimine-mediated DNA transfection and the proton sponge hypothesis. J. Gene Med. 7, 657-663.

(24) Zou, S. M., Erbacher, P., Remy, J. S., and Behr, J. P. (2000) Systemic linear polyethylenimine (L-PEI)-mediated gene delivery in the mouse. J. Gene Med. 2, 128-134.

(25) Wightman, L., Kircheis, R., Rossler, V., Carotta, S., Ruzicka, R., Kursa, M., and Wagner, E. (2001) Different behavior of branched and linear polyethylenimine for gene delivery in vitro and in vivo. J. Gene Med. 3, 362-372.

(26) Jeong, G. J., Byun, H. M., Kim, J. M., Yoon, H., Choi, H. G., Kim, W. K., Kim, S. J., and Oh, Y. K. (2007) Biodistribution and tissue expression kinetics of plasmid DNA complexed with polyethylenimines of different molecular weight and structure. J. Controlled Release 118, $118-125$.

(27) Werth, S., Urban-Klein, B., Dai, L., Hobel, S., Grzelinski, M., Bakowsky, U., Czubayko, F., and Aigner, A. (2006) A low molecular weight fraction of polyethylenimine (PEI) displays increased transfection efficiency of DNA and siRNA in fresh or lyophilized complexes. J. Controlled Release 112, 257-270.

(28) Russ, V., Elfberg, H., Thoma, C., Kloeckner, J., Ogris, M., and Wagner, E. (2008) Novel degradable oligoethylenimine acrylate esterbased pseudodendrimers for in vitro and in vivo gene transfer. Gene Ther. $15,18-29$.

(29) Shir, A., Ogris, M., Wagner, E., and Levitzki, A. (2006) EGF receptor-targeted synthetic double-stranded RNA eliminates glioblastoma, breast cancer, and adenocarcinoma tumors in mice. PLoS Med. 3, e6.

(30) Binauld, S., Damiron, D., Connal, L. A., Hawker, C. J., and Drockenmuller, E. (2011) Precise synthesis of molecularly defined oligomers and polymers by orthogonal iterative divergent/convergent approaches. Macromol. Rapid Commun. 32, 147-168.

(31) Lutz, J.-F. (2010) Sequence-controlled polymerizations: the next Holy Grail in polymer science?. Polym. Chem. 1, 55-62.

(32) Matyjaszewski, K., and Tsarevsky, N. V. (2009) Nanostructured functional materials prepared by atom transfer radical polymerization. Nat. Chem. 1, 276-288.

(33) Aoshima, S., and Kanaoka, S. (2009) A renaissance in living cationic polymerization. Chem. Rev. 109, 5245-5287.

(34) Adams, N., and Schubert, U. S. (2007) Poly(2-oxazolines) in biological and biomedical application contexts. Adv. Drug Delivery Rev. 59, 1504-1520.

(35) Bonnet, M. E., Erbacher, P., and Bolcato-Bellemin, A. L. (2008) Systemic delivery of DNA or siRNA mediated by linear polyethylenimine (L-PEI) does not induce an inflammatory response. Pharm. Res. 25, 2972-2982.

(36) Sidi, A. A., Ohana, P., Benjamin, S., Shalev, M., Ransom, J. H., Lamm, D., Hochberg, A., and Leibovitch, I. (2008) Phase I/II marker lesion study of intravesical BC-819 DNA plasmid in H19 over expressing superficial bladder cancer refractory to bacillus Calmette-Guerin. J. Urol. 180, 2379-2383.

(37) Kukowska-Latallo, J. F., Bielinska, A. U., Johnson, J., Spindler, R., Tomalia, D. A., and Baker, J. R., Jr. (1996) Efficient transfer of genetic material into mammalian cells using Starburst polyamidoamine dendrimers. Proc. Natl. Acad. Sci. U.S.A. 93, 4897-4902.

(38) Crespo, L., Sanclimens, G., Pons, M., Giralt, E., Royo, M., and Albericio, F. (2005) Peptide and amide bond-containing dendrimers. Chem. Rev. 105, 1663-1681.

(39) Denkewalter, R. G., Kolc, J., and Lukasavage, W. J. (1981) U.S. Patent 4289872.
(40) Merrifield, R. B. (1963) Solid phase peptide synthesis. I. The synthesis of a tetrapeptide. J. Am. Chem. Soc. 85, 2149-2154.

(41) Tam, J. P. (1988) Synthetic peptide vaccine design: synthesis and properties of a high-density multiple antigenic peptide system. Proc. Nat. Acad. Sci. U.S.A. 85, 5409-5413.

(42) Eom, K. D., Park, S. M., Tran, H. D., Kim, M. S., Yu, R. N., and Yoo, H. (2007) Dendritic $\alpha, \varepsilon$-poly(L-lysine)s as delivery agents for antisense oligonucleotides. Pharm. Res. 24, 1581-1589.

(43) Ohsaki, M., Okuda, T., Wada, A., Hirayama, T., Niidome, T., and Aoyagi, H. (2002) In vitro gene transfection using dendritic poly(Llysine). Bioconjugate Chem. 13, 510-517.

(44) Kawano, T., Okuda, T., Aoyagi, H., and Niidome, T. (2004) Long circulation of intravenously administered plasmid DNA delivered with dendritic poly(L-lysine) in the blood flow. J. Controlled Release 99, 329-337.

(45) Okuda, T., Sugiyama, A., Niidome, T., and Aoyagi, H. (2004) Characters of dendritic poly(L-lysine) analogues with the terminal lysines replaced with arginines and histidines as gene carriers in vitro. Biomaterials 25, 537-544.

(46) Chen, Q. R., Zhang, L., Stass, S. A., and Mixson, A. J. (2001) Branched co-polymers of histidine and lysine are efficient carriers of plasmids. Nucleic Acids Res. 29, 1334-1340.

(47) Chen, Q. R., Zhang, L., Luther, P. W., and Mixson, A. J. (2002) Optimal transfection with the HK polymer depends on its degree of branching and the $\mathrm{pH}$ of endocytic vesicles. Nucleic Acids Res. 30, 1338-1345.

(48) Leng, Q., Scaria, P., Zhu, J., Ambulos, N., Campbell, P., and Mixson, A. J. (2005) Highly branched HK peptides are effective carriers of siRNA. J. Gene Med. 7, 977-986.

(49) Leng, Q., and Mixson, A. J. (2005) Small interfering RNA targeting Raf-1 inhibits tumor growth in vitro and in vivo. Cancer Gene Ther. 12, 682-690.

(50) Sakthivel, T., Toth, I., and Florence, A. T. (1998) Synthesis and physicochemical properties of lipophilic polyamide dendrimers. Pharm. Res. 15, 776-782.

(51) Shah, D. S., Sakthivel, T., Toth, I., Florence, A. T., and Wilderspin, A. F. (2000) DNA transfection and transfected cell viability using amphipathic asymmetric dendrimers. Int. J. Pharm. 208, 41-48.

(52) Ravina, M., Paolicelli, P., Seijo, B., and Sanchez, A. (2010) Knocking down gene expression with dendritic vectors. Mini Rev. Med. Chem. 10, 73-86.

(53) Haensler, J., and Szoka, F. C., Jr. (1993) Polyamidoamine cascade polymers mediate efficient transfection of cells in culture. Bioconjugate Chem. 4, 372-379.

(54) Bielinska, A., Kukowska-Latallo, J. F., Johnson, J., Tomalia, D. A., and Baker, J. R. (1996) Regulation of in vitro gene expression using antisense oligonucleotides or antisense expression plasmids transfected using starburst PAMAM dendrimers. Nucleic Acids Res. 24, 2176-2182.

(55) Tang, M. X., Redemann, C. T., and Szoka, F. C., Jr. (1996) In vitro gene delivery by degraded polyamidoamine dendrimers. Bioconjugate Chem. 7, 703-714.

(56) Yoo, H., Sazani, P., and Juliano, R. L. (1999) PAMAM dendrimers as delivery agents for antisense oligonucleotides. Pharm. Res. 16, 1799-1804.

(57) Choi, J. S., Nam, K., Park, J.-y., Kim, J.-B., Lee, J.-K., and Park, J.-s. (2004) Enhanced transfection efficiency of PAMAM dendrimer by surface modification with L-arginine. J. Controlled Release 99, 445-456.

(58) Nam, H. Y., Hahn, H. J., Nam, K., Choi, W.-H., Jeong, Y., Kim, D.-E., and Park, J.-S. (2008) Evaluation of generations 2, 3 and 4 arginine modified PAMAM dendrimers for gene delivery. Int. J. Pharm. 363, 199-205.

(59) Yu, G. S., Bae, Y. M., Choi, H., Kong, B., Choi, I. S., and Choi, J. S. (2011) Synthesis of PAMAM dendrimer derivatives with enhanced buffering capacity and remarkable gene transfection efficiency. Bioconjugate Chem. 22, 1046-1055.

(60) Zinselmeyer, B. H., Mackay, S. P., Schatzlein, A. G., and Uchegbu, I. F. (2002) The lower-generation polypropylenimine 
dendrimers are effective gene-transfer agents. Pharm. Res. 19, 960967.

(61) Schatzlein, A. G., Zinselmeyer, B. H., Elouzi, A., Dufes, C., Chim, Y. T. A., Roberts, C. J., Davies, M. C., Munro, A., Gray, A. I., and Uchegbu, I. F. (2005) Preferential liver gene expression with polypropylenimine dendrimers. J. Controlled Release 101, 247-258.

(62) Russ, V., Gunther, M., Halama, A., Ogris, M., and Wagner, E. (2008) Oligoethylenimine-grafted polypropylenimine dendrimers as degradable and biocompatible synthetic vectors for gene delivery. J. Controlled Release 132, 131-140.

(63) Plank, C., Tang, M. X., Wolfe, A. R., and Szoka, F. C., Jr. (1999) Branched cationic peptides for gene delivery: role of type and number of cationic residues in formation and in vitro activity of DNA polyplexes. Hum. Gene Ther. 10, 319-332.

(64) Wagner, E., Zenke, M., Cotten, M., Beug, H., and Birnstiel, M. L. (1990) Transferrin-polycation conjugates as carriers for DNA uptake into cells. Proc. Natl. Acad. Sci. U.S.A. 87, 3410-3414.

(65) Cotten, M., Langle-Rouault, F., Kirlappos, H., Wagner, E., Mechtler, K., Zenke, M., Beug, H., and Birnstiel, M. L. (1990) Transferrin-polycation-mediated introduction of DNA into human leukemic cells: stimulation by agents that affect the survival of transfected DNA or modulate transferrin receptor levels. Proc. Natl. Acad. Sci. U.S.A. 87, 4033-4037.

(66) Wyman, T. B., Nicol, F., Zelphati, O., Scaria, P. V., Plank, C., and Szoka, F. C., Jr. (1997) Design, synthesis, and characterization of a cationic peptide that binds to nucleic acids and permeabilizes bilayers. Biochemistry 36, 3008-3017.

(67) McKenzie, D. L., Kwok, K. Y., and Rice, K. G. (2000) A potent new class of reductively activated peptide gene delivery agents. J. Biol. Chem. 275, 9970-9977.

(68) McKenzie, D. L., Smiley, E., Kwok, K. Y., and Rice, K. G. (2000) Low molecular weight disulfide cross-linking peptides as nonviral gene delivery carriers. Bioconjugate Chem. 11, 901-909.

(69) Read, M. L., Bremner, K. H., Oupicky, D., Green, N. K., Searle, P. F., and Seymour, L. W. (2003) Vectors based on reducible polycations facilitate intracellular release of nucleic acids. J. Gene Med. $5,232-245$.

(70) Kim, S. W., Kim, N. Y., Choi, Y. B., Park, S. H., Yang, J. M., and Shin, S. (2010) RNA interference in vitro and in vivo using an arginine peptide/siRNA complex system. J. Controlled Release 143, 335-343.

(71) Liu, Y., and Reineke, T. M. (2010) Degradation of poly(glycoamidoamine) DNA delivery vehicles: polyamide hydrolysis at physiological conditions promotes DNA release. Biomacromolecules 11, 316-325.

(72) Prevette, L. E., Lynch, M. L., and Reineke, T. M. (2010) Amide spacing influences pDNA binding of poly(amidoamine)s. Biomacromolecules 11, 326-332.

(73) McLendon, P. M., Fichter, K. M., and Reineke, T. M. (2010) Poly (glycoamidoamine) vehicles promote $\mathrm{pDNA}$ uptake through multiple routes and efficient gene expression via caveolae-mediated endocytosis. Mol. Pharmaceutics 7, 738-750.

(74) Hartmann, L. (2011) Polymers for control freaks: sequencedefined poly(amidoamine)s and their biomedical applications. Macromol. Chem. Phys. 212, 8-13.

(75) Hartmann, L., and Börner, H. G. (2009) Precision polymers: monodisperse, monomer-sequence-defined segments to target future demands of polymers in medicine. Adv. Mater. 21, 3425-3431.

(76) Hartmann, L., Hafele, S., Peschka-Suss, R., Antonietti, M., and Borner, H. G. (2008) Tailor-made poly(amidoamine)s for controlled complexation and condensation of DNA. Chemistry 14, 2025-2033.

(77) Hartmann, L., Häfele, S., Peschka-Süss, R., Antonietti, M., and Börner, H. G. (2007) Sequence positioning of disulfide linkages to program the degradation of monodisperse poly(amidoamines). Macromolecules 40, 7771-7776.

(78) Hartmann, L., Krause, E., Antonietti, M., and Borner, H. G. (2006) Solid-phase supported polymer synthesis of sequencedefined, multifunctional poly(amidoamines). Biomacromolecules 7, 1239-1244.
(79) Mosca, S., Wojcik, F., and Hartmann, L. (2011) Precise positioning of chiral building blocks in monodisperse, sequence-defined polyamides. Macromol. Rapid Commun. 32, 197-202.

(80) Schaffert, D., Badgujar, N., and Wagner, E. (2011) Novel Fmocpolyamino acids for solid-phase synthesis of defined polyamidoamines. Org. Lett. 13, 1586-1589.

(81) Schaffert, D., Troiber, C., Salcher, E. E., Fröhlich, T., Martin, I., Badgujar, N., Dohmen, C., Edinger, D., Kläger, R., Maiwald, G., Farkasova, K., Seeber, S., Jahn-Hofmann, K., Hadwiger, P., and Wagner, E. (2011) Solid-phase synthesized sequence-defined T-shape, i-shape and U-shape polymers for pDNA and siRNA delivery. Angew. Chem. Int. Ed. 50, in press, DOI: 10.1002 /anie.201102165.

(82) Blessing, T., Remy, J. S., and Behr, J. P. (1998) Monomolecular collapse of plasmid DNA into stable virus-like particles. Proc. Natl. Acad. Sci. U.S.A. 95, 1427-1431.

(83) Dauty, E., Remy, J.-S., Blessing, T., and Behr, J.-P. (2001) Dimerizable cationic detergents with a low $\mathrm{cmc}$ condense plasmid DNA into nanometric particles and transfect cells in culture. J. Am. Chem. Soc. 123, 9227-9234.

(84) Zuber, G., Dontenwill, M., and Behr, J.-P. (2009) Synthetic viruslike particles for targeted gene delivery to $\alpha \mathrm{v} \beta 3$ integrin-presenting endothelial cells. Mol. Pharmaceutics 6, 1544-1552.

(85) Chittimalla, C., Zammut-Italiano, L., Zuber, G., and Behr, J.-P. (2005) Monomolecular DNA nanoparticles for intravenous delivery of genes. J. Am. Chem. Soc. 127, 11436-11441.

(86) Xu, R., and Lu, Z.-R. (2011) Design, synthesis and evaluation of spermine-based $\mathrm{pH}$-sensitive amphiphilic gene delivery systems: multifunctional non-viral gene carriers. Sci. China Chem. 54, 359-368.

(87) Xu, R., Wang, X.-L., and Lu, Z.-R. (2010) New amphiphilic carriers forming $\mathrm{pH}$-sensitive nanoparticles for nucleic acid delivery. Langmuir 26, 13874-13882.

(88) Wang, X.-L., Xu, R., and Lu, Z.-R. (2009) A peptide-targeted delivery system with $\mathrm{pH}$-sensitive amphiphilic cell membrane disruption for efficient receptor-mediated siRNA delivery. J. Controlled Release 134, 207-213.

(89) Wang, X.-L., Xu, R., Wu, X., Gillespie, D., Jensen, R., and Lu, Z.-R. (2009) Targeted systemic delivery of a therapeutic siRNA with a multifunctional carrier controls tumor proliferation in mice. Mol. Pharmaceutics 6, 738-746.

(90) Philipp, A., Zhao, X., Tarcha, P., Wagner, E., and Zintchenko, A. (2009) Hydrophobically modified oligoethylenimines as highly efficient transfection agents for siRNA delivery. Bioconjugate Chem. 20, 2055-2061.

(91) Asai, T., Matsushita, S., Kenjo, E., Tsuzuku, T., Yonenaga, N., Koide, H., Hatanaka, K., Dewa, T., Nango, M., Maeda, N., Kikuchi, H., and Oku, N. (2011) Dicetyl phosphate-tetraethylenepentamine-based liposomes for systemic siRNA delivery. Bioconjugate Chem. 22, 429-435.

(92) Asai, T., and Oku, N. (2010) Angiogenic vessel-targeting DDS by liposomalized oligopeptides. Methods Mol. Biol. 605, 335-347.

(93) Damen, M., Aarbiou, J., van Dongen, S. F., Buijs-Offerman, R. M., Spijkers, P. P., van den Heuvel, M., Kvashnina, K., Nolte, R. J., Scholte, B. J., and Feiters, M. C. (2010) Delivery of DNA and siRNA by novel gemini-like amphiphilic peptides. J. Controlled Release 145, 33-39.

(94) Akinc, A., Zumbuehl, A., Goldberg, M., Leshchiner, E. S., Busini, V., Hossain, N., Bacallado, S. A., Nguyen, D. N., Fuller, J., Alvarez, R., Borodovsky, A., Borland, T., Constien, R., de Fougerolles, A., Dorkin, J. R., Narayanannair, J. K., Jayaraman, M., John, M., Koteliansky, V., Manoharan, M., Nechev, L., Qin, J., Racie, T., Raitcheva, D., Rajeev, K. G., Sah, D. W., Soutschek, J., Toudjarska, I., Vornlocher, H. P., Zimmermann, T. S., Langer, R, and Anderson, D. G. (2008) A combinatorial library of lipid-like materials for delivery of RNAi therapeutics. Nat. Biotechnol. 26, 561-569.

(95) Akinc, A., Goldberg, M., Qin, J., Dorkin, J. R., Gamba-Vitalo, C., Maier, M., Jayaprakash, K. N., Jayaraman, M., Rajeev, K. G., Manoharan, M., Koteliansky, V., Rohl, I., Leshchiner, E. S., Langer, R., and Anderson, D. G. (2009) Development of lipidoid-siRNA formulations for systemic delivery to the liver. Mol. Ther. 17, 872-879.

(96) Mahon, K. P., Love, K. T., Whitehead, K. A., Qin, J., Akinc, A., Leshchiner, E., Leshchiner, I., Langer, R., and Anderson, D. G. (2010) 
Combinatorial approach to determine functional group effects on lipidoid-mediated siRNA delivery. Bioconjugate Chem. 21, 1448-1454.

(97) Love, K. T., Mahon, K. P., Levins, C. G., Whitehead, K. A., Querbes, W., Dorkin, J. R., Qin, J., Cantley, W., Qin, L. L., Racie, T., Frank-Kamenetsky, M., Yip, K. N., Alvarez, R., Sah, D. W., de Fougerolles, A., Fitzgerald, K., Koteliansky, V., Akinc, A., Langer, R. and Anderson, D. G. (2010) Lipid-like materials for low-dose, in vivo gene silencing. Proc. Natl. Acad. Sci. U.S.A. 107, 1864-1869.

(98) de Bruin, K., Ruthardt, N., von Gersdorff, K., Bausinger, R., Wagner, E., Ogris, M., and Brauchle, C. (2007) Cellular dynamics of EGF receptor-targeted synthetic viruses. Mol. Ther. 15, 1297-1305.

(99) Schaffert, D., Kiss, M., Rodl, W., Shir, A., Levitzki, A., Ogris, M., and Wagner, E. (2011) Poly(I:C)-mediated tumor growth suppression in EGF-receptor overexpressing tumors using EGF-polyethylene glycollinear polyethylenimine as carrier. Pharm. Res. 28, 731-741.

(100) Pons, B., Mouhoubi, L., Adib, A., Godzina, P., Behr, J. P., and Zuber, G. (2006) $\omega$-Hydrazino linear polyethylenimine: a monoconjugation building block for nucleic acid delivery. Chembiochem 7, 303-309.

(101) Hein, C., Liu, X.-M., and Wang, D. (2008) Click chemistry, a powerful tool for pharmaceutical sciences. Pharm. Res. 25, 2216-2230.

(102) Lutz, J.-F., and Zarafshani, Z. (2008) Efficient construction of therapeutics, bioconjugates, biomaterials and bioactive surfaces using azide-alkyne "click" chemistry. Adv. Drug Delivery Rev. 60, 958-970.

(103) Moses, J. E., and Moorhouse, A. D. (2007) The growing applications of click chemistry. Chem. Soc. Rev. 36, 1249-1262.

(104) Orski, S. V., Poloukhtine, A. A., Arumugam, S., Mao, L., Popik, V. V., and Locklin, J. (2010) High density orthogonal surface immobilization via photoactivated copper-free click chemistry. J. Am. Chem. Soc. 132, 11024-11026.

(105) Kolb, H. C., Finn, M. G., and Sharpless, K. B. (2001) Click chemistry: diverse chemical function from a few good reactions. Angew. Chem. Int. Ed. 40, 2004-2021.

(106) Rostovtsev, V. V., Green, L. G., Fokin, V. V., and Sharpless, K. B. (2002) A stepwise huisgen cycloaddition process: copper(I)catalyzed regioselective "ligation" of azides and terminal alkynes. Angew. Chem. Int. Ed. 41, 2596-2599.

(107) Tornøe, C. W., Christensen, C., and Meldal, M. (2002) Peptidotriazoles on solid phase: [1,2,3]-triazoles by regiospecific copper(I)-catalyzed 1,3-dipolar cycloadditions of terminal alkynes to azides. J. Org. Chem. 67, 3057-3064.

(108) Mindt, T. L., Muller, C., Stuker, F., Salazar, J.-F., Hohn, A., Mueggler, T., Rudin, M., and Schibli, R. (2009) A "click chemistry" approach to the efficient synthesis of multiple imaging probes derived from a single precursor. Bioconjugate Chem. 20, 1940-1949.

(109) Schlossbauer, A., Schaffert, D., Kecht, J., Wagner, E., and Bein, T. (2008) Click chemistry for high-density biofunctionalization of mesoporous silica. J. Am. Chem. Soc. 130, 12558-12559.

(110) Chang, P. V., Prescher, J. A., Sletten, E. M., Baskin, J. M., Miller, I. A., Agard, N. J., Lo, A., and Bertozzi, C. R. (2010) Copper-free click chemistry in living animals. Proc. Natl. Acad. Sci. U.S.A. 107, 18211826.

(111) Jiang, X., Lok, M. C., and Hennink, W. E. (2007) Degradablebrushed pHEMA-pDMAEMA synthesized via ATRP and click chemistry for gene delivery. Bioconjugate Chem. 18, 2077-2084.

(112) Lee, C.-C., Grandinetti, G., McLendon, P. M., and Reineke, T. M. (2010) A polycation scaffold presenting tunable "click" sites: conjugation to carbohydrate ligands and examination of hepatocytetargeted pDNA delivery. Macromol. Biosci. 10, 585-598.

(113) Liu, J., Jiang, X., Xu, L., Wang, X., Hennink, W. E., and Zhuo, R. (2010) Novel reduction-responsive cross-linked polyethylenimine derivatives by click chemistry for nonviral gene delivery. Bioconjugate Chem. 21, 1827-1835.

(114) Srinivasachari, S., Liu, Y., Zhang, G., Prevette, L., and Reineke, T. M. (2006) Trehalose click polymers inhibit nanoparticle aggregation and promote pDNA delivery in serum. J. Am. Chem. Soc. 128, 8176-8184.

(115) Srinivasachari, S., and Reineke, T. M. (2009) Versatile supramolecular pDNA vehicles via "click polymerization" of $\beta$-cyclodextrin with oligoethyleneamines. Biomaterials 30, 928-938.
(116) van Dijk, M., Rijkers, D. T. S., Liskamp, R. M. J., van Nostrum, C. F., and Hennink, W. E. (2009) Synthesis and applications of biomedical and pharmaceutical polymers via click chemistry methodologies. Bioconjugate Chem. 20, 2001-2016.

(117) Lee, J. W., Kim, H. J., Han, S. C., Kim, J. H., and Jin, S.-H. (2008) Synthesis and characterization of poly (amido amine) dendrimer containing fluorene as a core chromophore. J. Nanosci. Nanotechnol. $8,4635-4639$.

(118) Lee, J. W., Kim, H. J., Han, S. C., Kim, J. H., and Jin, S.-H. (2008) Designing poly(amido amine) dendrimers containing core diversities by click chemistry of the propargyl focal point poly(amido amine) dendrons. J. Polym. Sci. Part A: Polym. Chem. 46, 1083-1097.

(119) Yu, H., Nie, Y., Dohmen, C., Li, Y., and Wagner, E. (2011) Epidermal growth factor-PEG functionalized PAMAM-pentaethylenehexamine dendron for targeted gene delivery produced by click chemistry. Biomacromolecules 12, 2039-2047.

(120) Huang, B., Desai, A., Zong, H., Tang, S., Leroueil, P., and Baker, J. R., Jr. (2011) Copper-free click conjugation of methotrexate to a PAMAM dendrimer platform. Tetrahedron Lett. 52, 1411-1414.

(121) Jayaprakash, K. N., Peng, C. G., Butler, D., Varghese, J. P., Maier, M. A., Rajeev, K. G., and Manoharan, M. (2010) Nonnucleoside building blocks for copper-assisted and copper-free click chemistry for the efficient synthesis of RNA conjugates. Org. Lett. 12, 5410-5413.

(122) Yamada, T., Peng, C. G., Matsuda, S., Addepalli, H., Jayaprakash, K. N., Alam, M. R., Mills, K., Maier, M. A., Charisse, K., Sekine, M., Manoharan, M., and Rajeev, K. G. (2011) Versatile site-specific conjugation of small molecules to siRNA using click chemistry. J. Org. Chem. $76,1198-1211$.

(123) Dawson, P., Muir, T., Clark-Lewis, I., and Kent, S. (1994) Synthesis of proteins by native chemical ligation. Science 266, 776-779.

(124) Byun, E., Kim, J., Kang, S. M., Lee, H., Bang, D., and Lee, H. (2010) Surface PEGylation via native chemical ligation. Bioconjugate Chem. 22, 4-8.

(125) Walker, G. F., Fella, C., Pelisek, J., Fahrmeir, J., Boeckle, S., Ogris, M., and Wagner, E. (2005) Toward synthetic viruses: endosomal $\mathrm{pH}$-triggered deshielding of targeted polyplexes greatly enhances gene transfer in vitro and in vivo. Mol. Ther. 11, 418-425.

(126) Knorr, V., Allmendinger, L., Walker, G. F., Paintner, F. F., and Wagner, E. (2007) An acetal-based PEGylation reagent for $\mathrm{pH}$ sensitive shielding of DNA polyplexes. Bioconjugate Chem. 18, 12181225.

(127) Fella, C., Walker, G. F., Ogris, M., and Wagner, E. (2008) Amine-reactive pyridylhydrazone-based PEG reagents for $\mathrm{pH}$-reversible PEI polyplex shielding. Eur. J. Pharm. Sci 34, 309-320.

(128) Rozema, D. B., Lewis, D. L., Wakefield, D. H., Wong, S. C., Klein, J. J., Roesch, P. L., Bertin, S. L., Reppen, T. W., Chu, Q., Blokhin, A. V., Hagstrom, J. E., and Wolff, J. A. (2007) Dynamic PolyConjugates for targeted in vivo delivery of siRNA to hepatocytes. Proc. Natl. Acad. Sci U.S.A. 104, 12982-12987.

(129) Nie, Y., Günther, M., Gu, Z., and Wagner, E. (2011) Pyridylhydrazone-based PEGylation for $\mathrm{pH}$-reversible lipopolyplex shielding. Biomaterials 32, 858-869.

(130) Leonetti, J. P., Degols, G., and Lebleu, B. (1990) Biological activity of oligonucleotide-poly(L-lysine) conjugates: mechanism of cell uptake 381. Bioconjugate Chem. 1, 149-153.

(131) Bulmus, V., Woodward, M., Lin, L., Murthy, N., Stayton, P., and Hoffman, A. (2003) A new pH-responsive and glutathionereactive, endosomal membrane-disruptive polymeric carrier for intracellular delivery of biomolecular drugs. J. Controlled Release 93, 105-120.

(132) Hoffman, A. S., Stayton, P. S., Press, O., Murthy, N., Lackey, C. A., Cheung, C., Black, F., Campbell, J., Fausto, N., Kyriakides, T. R., and Bornstein, P. (2002) Design of "smart" polymers that can direct intracellular drug delivery. Polym. Adv. Technnol. 13, 992-999.

(133) Zhu, L., and Mahato, R. I. (2010) Targeted delivery of siRNA to hepatocytes and hepatic stellate cells by bioconjugation. Bioconjugate Chem. 21, 2119-2127. 
(134) Nakagawa, T., Zhu, H., Morishima, N., Li, E., Xu, J., Yankner, B. A., and Yuan, J. (2000) Caspase-12 mediates endoplasmic-reticulumspecific apoptosis and cytotoxicity by amyloid- $\beta$. Nature $403,98-103$.

(135) Lönnberg, H. (2009) Solid-phase synthesis of oligonucleotide conjugates useful for delivery and targeting of potential nucleic acid therapeutics. Bioconjugate Chem. 20, 1065-1094.

(136) Jeong, J. H., Mok, H., Oh, Y.-K., and Park, T. G. (2008) siRNA conjugate delivery systems. Bioconjugate Chem. 20, 5-14.

(137) Thomas, M., Kularatne, S. A., Qi, L., Kleindl, P., Leamon, C. P., Hansen, M. J., and Low, P. S. (2009) Ligand-targeted delivery of small interfering RNAs to malignant cells and tissues. Ann. N.Y. Acad. Sci. $1175,32-39$.

(138) Soutschek, J., Akinc, A., Bramlage, B., Charisse, K., Constien, R., Donoghue, M., Elbashir, S., Geick, A., Hadwiger, P., Harborth, J., John, M., Kesavan, V., Lavine, G., Pandey, R. K., Racie, T., Rajeev, K. G., Rohl, I., Toudjarska, I., Wang, G., Wuschko, S., Bumcrot, D., Koteliansky, V., Limmer, S., Manoharan, M., and Vornlocher, H.-P. (2004) Therapeutic silencing of an endogenous gene by systemic administration of modified siRNAs. Nature 432, 173-178.

(139) Nishina, K., Unno, T., Uno, Y., Kubodera, T., Kanouchi, T., Mizusawa, H., and Yokota, T. (2008) Efficient in vivo delivery of siRNA to the liver by conjugation of $\alpha$-tocopherol. Mol. Ther. 16, 734-740.

(140) Kim, S. H., Jeong, J. H., Lee, S. H., Kim, S. W., and Park, T. G. (2006) PEG conjugated VEGF siRNA for anti-angiogenic gene therapy. J. Controlled Release 116, 123-129.

(141) Meyer, M., Dohmen, C., Philipp, A., Kiener, D., Maiwald, G., Scheu, C., Ogris, M., and Wagner, E. (2009) Synthesis and biological evaluation of a bioresponsive and endosomolytic siRNA-polymer conjugate. Mol. Pharmaceutics 6, 752-762.

(142) Oishi, M., Nagasaki, Y., Itaka, K., Nishiyama, N., and Kataoka, K. (2005) Lactosylated poly(ethylene glycol)-siRNA conjugate through acid-labile $\beta$-thiopropionate linkage to construct $\mathrm{pH}$-sensitive polyion complex micelles achieving enhanced gene silencing in hepatoma cells. J. Am. Chem. Soc. 127, 1624-1625.

(143) Zhu, L., Ye, Z., Cheng, K., Miller, D. D., and Mahato, R. I. (2007) Site-specific delivery of oligonucleotides to hepatocytes after systemic administration. Bioconjugate Chem. 19, 290-298.

(144) Meyer, M., Philipp, A., Oskuee, R., Schmidt, C., and Wagner, E. (2008) Breathing life into polycations: functionalization with $\mathrm{pH}-$ responsive endosomolytic peptides and polyethylene glycol enables siRNA delivery. J. Am. Chem. Soc. 130, 3272-3273.

(145) Philipp, A., Meyer, M., Zintchenko, A., and Wagner, E. (2011) Functional modification of amide-crosslinked oligoethylenimine for improved siRNA delivery. Reactive Funct. Polymers 71, 288-293. 